\title{
Article \\ Experimental Research on Mechanical Properties and Compression Constitutive Relationship of PVA Fiber-Reinforced Coral Concrete
}

\author{
Lan Rao ${ }^{1,2, * \mathbb{D}}$, Ling Wang ${ }^{1,3}$ and Yun Zheng ${ }^{3}$ \\ 1 School of Civil Engineering, Xi'an University of Architecture \& Technology, Xi'an 710055, China; \\ wangling_mcc@163.com \\ 2 School of Civil and Architectural Engineering, Kaifeng University, Kaifeng 475004, China \\ 3 Central Research Institute of Building and Construction Co., Ltd., MCC, Beijing 100088, China; nrcsc@139.com \\ * Correspondence: lanrao2017@xauat.edu.cn
}

check for

updates

Citation: Rao, L.; Wang, L.; Zheng, Y.

Experimental Research on

Mechanical Properties and

Compression Constitutive

Relationship of PVA Fiber-Reinforced

Coral Concrete. Materials 2022, 15,

1762. https://doi.org/10.3390/

ma15051762

Academic Editors: Dolores Eliche

Quesada and Dario De Domenico

Received: 27 September 2021

Accepted: 9 February 2022

Published: 26 February 2022

Publisher's Note: MDPI stays neutral with regard to jurisdictional claims in published maps and institutional affiliations.

Copyright: () 2022 by the authors. Licensee MDPI, Basel, Switzerland. This article is an open access article distributed under the terms and conditions of the Creative Commons Attribution (CC BY) license (https:/ / creativecommons.org/licenses/by/ $4.0 /)$.

\begin{abstract}
In this paper, the mechanical properties of coral concrete with different strength and different polyvinyl alcohol (PVA) fiber content under compression were experimentally investigated. The results show that adding an appropriate amount of PVA fiber could obtain satisfactory mechanical properties of coral concrete. The stress-strain constitutive relationship of plain and PVA fiberreinforced coral concrete was investigated by prism uniaxial compression test. The results shown that the incorporation of PVA fiber had a significant effect on limiting the development of concrete internal cracks, and effectively improved the mechanical properties of coral concrete after cracking, especially the toughness. Different constitutive models from previous research were used to describe the axial compressive stress-strain relationship of plain and PVA fiber-reinforced coral concrete, and a piecewise function model was finally selected which is most consistent with the experimental curve and its characteristic points. In addition, determination of critical parameters for the selected constitutive model was proposed, and experimental validations confirmed its accuracy.
\end{abstract}

Keywords: coral concrete; PVA fiber; mechanical property; stress-strain curve; constitutive relationship

\section{Introduction}

In recent years, many countries have increased their investment in ocean engineering in response to the increasing depletion of land resources. For example, the construction of artificial islands is receiving more attention in many coastal countries, and the sea sandbroken reef aggregate concrete material is also becoming a research focus in construction materials. For off-shore islands and reefs lacking traditional construction materials, the problem of cost increase is inevitable and unacceptable. Fortunately, the coral resources in many off-shore islands and reefs are rich. Therefore, inventing a new kind of concrete with the best use of coral resources becomes a potential approach in off-shore islands and reef engineering construction.

As early as the 1950s, the application and research of coral concrete had been started in the United States. Dempsey [1] and Narver [2] described the configuration requirements of coral concrete, and evaluated the coral concrete buildings. On some islands, such as Midway, Wake and Bikini, coral concrete was used to build airports and roads, and some of them are still in service [3]. In 1974, Howdyshell [4] investigated the coral concrete buildings, and confirmed that it was feasible to use coral aggregate instead of traditional coarse aggregate to prepare concrete. In 2015, Yuan [5] prepared high performance coral concrete with strength up to $60 \mathrm{MPa}$ using fly ash and slag instead of part of P.II52.5 ordinary Portland cement in the mix proportion of coral concrete. So far, many researches have been conducted on the mix proportion, strength and durability of coral concrete [6,7]. However, there are few researches completed in terms of its constitutive relationship, 
especially the constitutive relationship of fiber-reinforced coral concrete. As the constitutive relationship of concrete is one of the most important factors that determine the servicing capacity of concrete engineering structures, the existing research results of coral concrete are still not enough for detailed engineering application or performance-based engineering design, and further research is needed.

In 2000, Sun [8] studied the mechanical properties of coral aggregate and pointed out that coral particles had great compressibility and were prone to being broken in the process of compression and shear because of its high porosity, which might be the major factor affecting the ductility of coral concrete, and lead to its mechanical performance significantly different from ordinary aggregate concrete, light aggregate concrete and recycled aggregate concrete [9-13]. It deserved more research to improve the ductility of coral concrete so as to better meet the ductility demand of engineering structures. In recent years, many scholars have carried out researches on fiber reinforced concrete, such as Mukhopadhyay [14], Pereira [15], Nia [16], and Yoo [17], which shown that fibers had significant effects on the crack resistance, toughness, impact resistance and other performances of the concrete. From 2014 to 2016, Wang [18-20], studied the basic mechanical indices of coral concrete mixed with carbon fiber, sisal fiber and polypropylene fiber, respectively. The results show that the fiber significantly improved the mechanical properties of coral concrete.

In general, due to the particularity of the marine environment, the durability of concrete structures with different kinds of fibers is obviously different. Coral concrete, as a special building material in the marine environment, not only requires the fiber to play a role of toughening and strengthening, but also to present the properties of weather resistance and corrosion resistance etc. Therefore, compared with other fibers, polyvinyl alcohol (PVA) fiber with low price and excellent performance might be a better choice.

PVA fiber is a kind of synthetic fiber with many advantages, such as high strength, high elasticity, good wear resistance, strong acid-base resistance, and good corrosion resistance [21]. Due to its strong affinity with cement base material and non-toxic or pollution characteristics, it has become one of the new generations of high-tech green building materials. Existing research results show that the addition of PVA fiber could effectively improve the strength, ductility [22,23], crack resistance [24] and durability [21] of concrete. However, there are few investigations on PVA fiber-reinforced coral aggregate concrete, which will be investigated in this study to supplement.

In this study, the experiments on cube compressive strength, prism axial compressive strength of plain and PVA fiber-reinforced coral concrete were carried out. Based on the experiment results, the influences of PVA fiber on the compression strength, elastic modulus and Poisson's ratio of coral concrete were studied. Furthermore, the compression stress-strain curve characteristics of plain and PVA fiber-reinforced coral concrete were comparatively studied, and the constitutive model for uniaxial compression stress-strain curve of plain and PVA fiber-reinforced coral concrete was also proposed. The results might be referable for engineering application or performance-based engineering design.

\section{Materials and Methods}

\subsection{Materials and Properties}

The coral from a Southern China Sea island was broken into irregular particles with a maximum diameter of $26.5 \mathrm{~mm}$. After sieving, aggregate with continuous particle size of 4.75 to $26.5 \mathrm{~mm}$ was used as coarse aggregate (Figure 1a), and particles with continuous particle size less than $4.75 \mathrm{~mm}$ was used as fine aggregate (Figure 1b), which had a fineness modulus of 1.7. According to ASTM C33/C33M-2018 [25] and GB/T 17431.2-2010 [26] the particle size distribution and the physical properties of coral aggregate were measured as shown in Figure 1c and Table 1. 


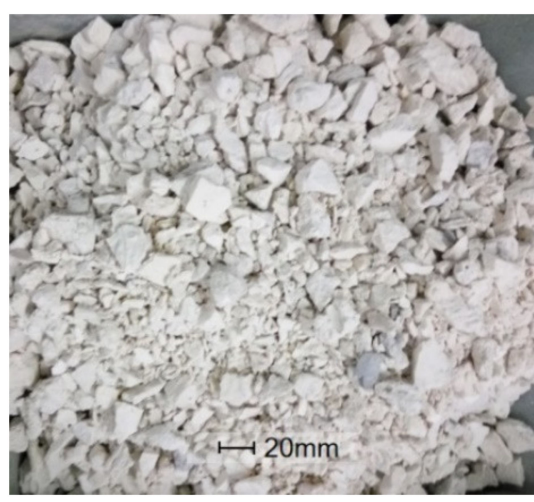

(a)

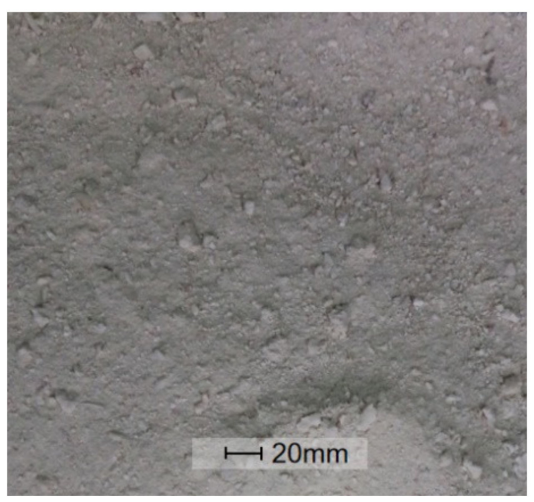

(b)

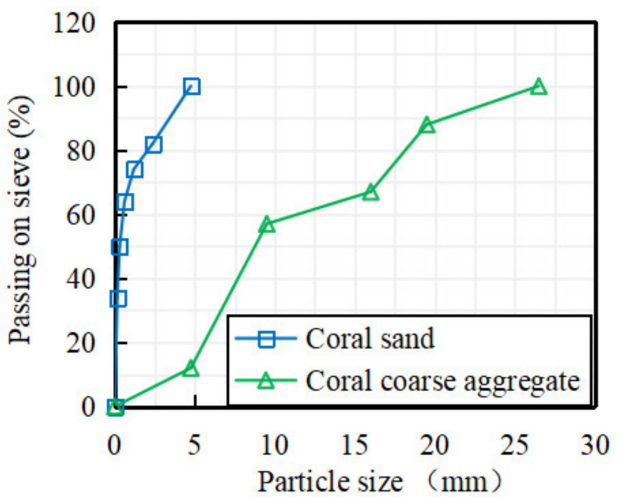

(c)

Figure 1. Coral aggregate from a South China Sea island. (a) Coarse aggregate, (b) Fine aggregate, (c) Size distribution of coral aggregate.

Table 1. Physical property of coral aggregate.

\begin{tabular}{cccccc}
\hline Type & $\begin{array}{c}\text { Bulk Density } \\
\left(\mathbf{k g} / \mathbf{m}^{\mathbf{3}} \mathbf{)}\right.\end{array}$ & $\begin{array}{c}\text { Apparent Density } \\
\left(\mathbf{k g} / \mathbf{m}^{\mathbf{3}}\right)\end{array}$ & $\begin{array}{c}\text { Water Absorption } \\
\mathbf{( \% )}\end{array}$ & $\begin{array}{c}\text { Cylindrical Strength } \\
\mathbf{( M P a )}\end{array}$ & $\begin{array}{c}\text { Void Content } \\
(\mathbf{\%})\end{array}$ \\
\hline Coarse aggregate & 888 & 1870 & 12 & 3.8 & 52.5 \\
\hline Fine aggregate & 1392 & 2380 & 10 & - & 42.5 \\
\hline
\end{tabular}

Ordinary Portland Cement P. O 42.5 (OPC), slag (SG) and silica fume (SF) were used in the tested mixtures, their chemical compositions are shown in Table 2. In this test, the coral concrete was also mixed with PVA fiber, the details of PVA fiber's physical properties are shown in Table 3. According to the literature [27], artificial seawater was prepared according to the composition of the seawater in the Southern China Sea, and its chemical composition is given in Table 4. Polycarboxylate superplasticizer (SP) with solid content of $40 \%$ was used in the test.

Table 2. Chemical composition of cementitious materials.

\begin{tabular}{|c|c|c|c|c|c|c|c|c|c|c|}
\hline \multirow{2}{*}{$\begin{array}{c}\text { Test } \\
\text { Project }\end{array}$} & \multicolumn{7}{|c|}{ W\% } & \multirow{2}{*}{$\begin{array}{l}\text { Specific Surface } \\
\text { Area }\left(\mathrm{m}^{2} \cdot \mathrm{kg}^{-1}\right)\end{array}$} & \multirow{2}{*}{$\begin{array}{l}\text { Loss of } \\
\text { Ignition }\end{array}$} & \multirow{2}{*}{$\begin{array}{l}\text { Density } \\
\left(\mathrm{kg} / \mathrm{m}^{3}\right)\end{array}$} \\
\hline & $\mathrm{SiO}_{2}$ & $\mathrm{Al}_{2} \mathrm{O}_{3}$ & $\mathrm{Fe}_{2} \mathrm{O}_{3}$ & $\mathrm{CaO}$ & $\mathrm{MgO}$ & $\mathrm{SO}_{3}$ & LOI & & & \\
\hline OPC & 22.47 & 4.83 & 2.97 & 59.28 & 1.97 & 2.39 & - & - & 2.75 & 3100 \\
\hline SG & 33.65 & 15.3 & 0.46 & 35.42 & 10.2 & 0.70 & 0.15 & 424 & 0.71 & 2940 \\
\hline SF & 95.70 & 0.54 & 0.06 & 0.76 & 0.54 & 0.01 & 1.32 & 18,465 & 2.95 & 330 \\
\hline
\end{tabular}

Table 3. Physical properties of PVA fiber.

\begin{tabular}{cccccc}
\hline $\begin{array}{c}\text { Length } \\
(\mathbf{m m})\end{array}$ & $\begin{array}{c}\text { Diameter } \\
(\boldsymbol{\mu m})\end{array}$ & $\begin{array}{c}\text { Density } \\
\left(\mathbf{k g} / \mathbf{m}^{\mathbf{3}}\right)\end{array}$ & $\begin{array}{c}\text { Young Modulus } \\
(\mathbf{G} \mathbf{p a})\end{array}$ & $\begin{array}{c}\text { Tensile Strength } \\
(\mathbf{M p a})\end{array}$ & $\begin{array}{c}\text { Elongation } \\
(\mathbf{\%})\end{array}$ \\
\hline $11-13$ & $42-46$ & 1290 & 33.8 & 1430 & $6-11$ \\
\hline
\end{tabular}

Table 4. Chemical composition of artificial seawater (g/L).

\begin{tabular}{cccccc}
\hline $\mathbf{N a C l}$ & $\mathbf{M g C l}_{\mathbf{2}} \cdot \mathbf{6 H 2 0}$ & $\mathbf{N a}_{\mathbf{2}} \mathbf{S O}_{\mathbf{4}}$ & $\mathbf{C a C l}_{\mathbf{2}}$ & $\mathbf{K C l}$ & $\mathrm{NaHCO}_{3}$ \\
\hline 22.2 & 11.3 & 3.86 & 1.08 & 0.75 & 0.21 \\
\hline
\end{tabular}

\subsection{Mix Proportion}

According to Chinese technical specification for lightweight aggregate concrete (JGJ512002) [28] and Chinese standard for test methods for fiber reinforced concrete (CECS13: 2009) [29], different mix proportions were designed in this test. Through the equal quality 
substitution method, silica fume with substitution rate (by weight) of $5-7.5 \%$ and slag with substitution rate of 15-22.5\% were used to replace part of cement to prepare coral concrete. Based on C40 specimen group, the mix proportions of coral concrete with different fiber content were designed, and compared with the reference group (C40), the fiber groups (FC1-FC4) were only different in fiber content, the fiber dosages were $0.8125 \mathrm{~kg} / \mathrm{m}^{3}$, $1.625 \mathrm{~kg} / \mathrm{m}^{3}, 3.25 \mathrm{~kg} / \mathrm{m}^{3}$ and $6.5 \mathrm{~kg} / \mathrm{m}^{3}$, respectively, as shown in Table 5 .

Table 5. Coral concrete mix proportions.

\begin{tabular}{|c|c|c|c|c|c|c|c|c|c|}
\hline \multirow{2}{*}{ Groups } & \multicolumn{8}{|c|}{ Mix Proportions $\left(\mathrm{kg} / \mathrm{m}^{3}\right)$} & \multirow{2}{*}{$\begin{array}{c}\text { Total } \\
w / b\end{array}$} \\
\hline & OPC & S95 & SF95 & Coarse Aggregate & Coral Sand & Total Water & SP & Fiber & \\
\hline $\mathrm{C} 25$ & 255 & 82 & 27 & 729 & 729 & 246 & 2.9 & 0 & 0.68 \\
\hline C30 & 288 & 93 & 31 & 709 & 709 & 241 & 3.7 & 0 & 0.58 \\
\hline C35 & 420 & 135 & 45 & 700 & 700 & 235 & 7.2 & 0 & 0.39 \\
\hline $\mathrm{C} 40$ & 480 & 90 & 30 & 625 & 625 & 220 & 10 & 0 & 0.37 \\
\hline FC1 & 480 & 90 & 30 & 625 & 625 & 220 & 10 & 0.8125 & 0.37 \\
\hline FC2 & 480 & 90 & 30 & 625 & 625 & 220 & 10 & 1.625 & 0.37 \\
\hline FC3 & 480 & 90 & 30 & 625 & 625 & 220 & 10 & 3.25 & 0.37 \\
\hline FC4 & 480 & 90 & 30 & 625 & 625 & 220 & 10 & 6.5 & 0.37 \\
\hline
\end{tabular}

Note: " $w / b$ " is water-binder ratio, where, " $w$ " denotes dosage of water in the mix, in $\mathrm{kg} / \mathrm{m}^{3} ; b=\mathrm{m}_{\mathrm{C}}+\mathrm{m}_{\mathrm{SG}}+\mathrm{m}_{\mathrm{SF}}$, $\mathrm{m}_{\mathrm{C}}, \mathrm{m}_{\mathrm{SG}}$ and $\mathrm{m}_{\mathrm{SF}}$ represent the dosage of $\mathrm{OPC}, \mathrm{SG}, \mathrm{SF}$, respectively, in $\mathrm{kg} / \mathrm{m}^{3}$.

\subsection{Specimen Production}

Due to the water-absorption and water-release characteristics of coral aggregates [8,30], the problem of high drying shrinkage of coral concrete is prominent [10], however, investigations suggested that pre-wetting aggregate and adding shrinkage reducing agent could effectively inhibit the shrinkage deformation of coral concrete [31]. Hence, the coral aggregate was pre wetted during the preparation of coral concrete [32], and the preparation procedure of coral concrete was formulated as follows: (1) Added the coarse and fine gravel aggregate of coral coarse into the mixer and stirred for 1 min; (2) Added about $50 \%$ of the seawater which could be absorbed by the aggregate and stirred for 1-2 min; (3) Added the cementitious material and stirred for $1 \mathrm{~min}$; (4) Added PVA fibers evenly to the mix while stirring, and continuously stirred for 1-2 min; (5) Added the polycarboxylate superplasticizer into the remaining water and mixed well, and then added it to the mixture in 2-3 times and mixed continuously for 1-2 min. The slump and dispersion of coral concrete were measured immediately after mixing. After the concrete was placed in molds of specific size, vibrated on a vibration table, the exposed surface concrete was covered with plastic film to prevent water dispersion, and then all specimens were demolded after curing under normal temperature $\left(20 \pm 3{ }^{\circ} \mathrm{C}\right)$ for $24 \mathrm{~h}$. Finally, all the pieces were placed in the standard curing room for 28 days until being tested.

The test methods of mechanical properties of coral concrete were conducted according to Chinese standard for method of mechanical properties on ordinary concrete (GB/T 50081-2002) [33], and eight groups of specimens were prepared. Each group included nine specimens, of which three specimens with dimensions of $100 \mathrm{~mm} \times 100 \mathrm{~mm} \times 100 \mathrm{~mm}$ were used to test the cubic compressive strength, three specimens with dimensions of $100 \mathrm{~mm} \times 100 \mathrm{~mm} \times 300 \mathrm{~mm}$ were used to test the prism axial compression, and three specimens with dimensions of $100 \mathrm{~mm} \times 100 \mathrm{~mm} \times 300 \mathrm{~mm}$ were used for the uniaxial compressive stress-strain curve test.

\subsection{Test Procedures}

The electro-hydraulic servo universal testing machine (WAW-2000D, Jinan Zhonglu Chang testing machine Manufacturing Co., LTD, Jinan, China) was used for uniaxial compression test, with a maximum capacity of $2000 \mathrm{kN}$, as shown in Figure 2. During the compression strength test, the loading speed was kept in a uniform loading speed of $0.5 \mathrm{kN} / \mathrm{s}$ until the failure. During the loading of stress-strain curve test, the first step was 
to preload with $1 \mathrm{kN} / \mathrm{s}$ to $15 \%$ of the estimated ultimate load and then unload. This step was repeated three times. The second step was to check the strain collection values of two sides of the test specimens to ensure alignment. After three preloads, keep loading to $60 \%$ of the estimated ultimate load at the speed of $1 \mathrm{kN} / \mathrm{s}$, and then continued to load until failure at the speed of $0.025 \mathrm{~mm} / \mathrm{min}$.

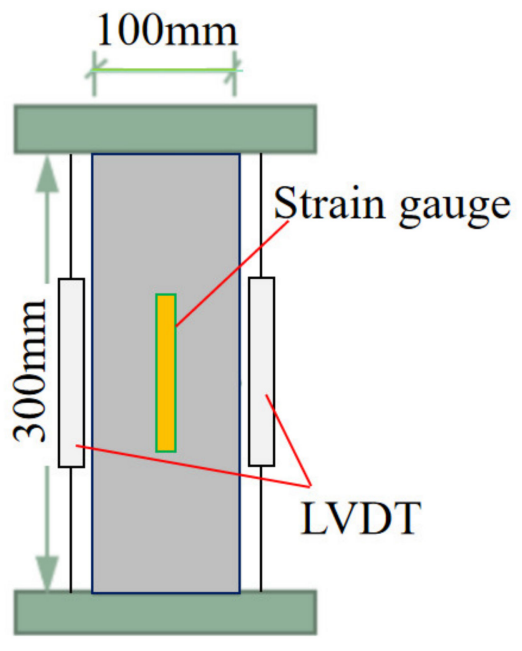

(a)

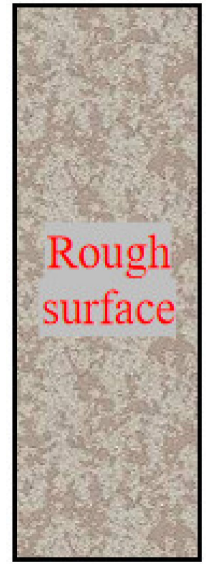

A

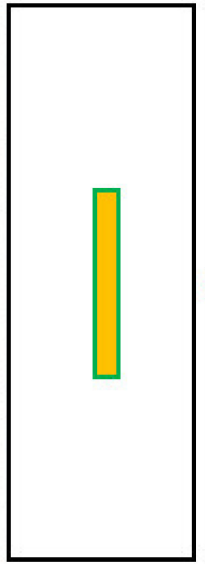

B

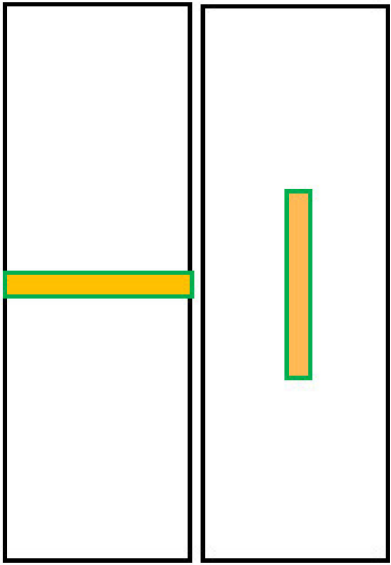

$\mathrm{C}$
$\mathrm{D}$

(b)

Figure 2. Test device and strain gauge arrangements. (a) Schematic diagram of test device, (b) Strain gauge diagram.

Three rubber-based strain gauges were pasted on each stress-strain curve test specimen, in which two longitudinal strain gauges were arranged at sides $B$ and $D$, and one transverse strain gauge at side $C$, respectively, as shown in Figure $2 b$ (as the specimen is molded, the surface side A is rough and uneven, so no strain gauge is set on side A), connected with the computer for synchronous strain acquisition before peak load, in addition, two linear voltage-displacement transducers (LVDT) were arranged in the both sides of the specimen to record the axial deformation. During the loading process, the load values of the test specimen were measured by the machine through the pressure sensors, then according to the measured data the computer automatically generated the curve of loading and unloading. The phenomenon was recorded during the test process. Due to the low strength and high brittleness of coral aggregate, the specimen generally cracked and then collapsed rapidly when it was loaded around the peak load, and therefore displacement gauge could just collect few data during the post peak stage.

\section{Results and Discussion}

\subsection{Basic Physical and Mechanical Properties \\ 3.1.1. Working Performance}

The tests of slump and dispersion were conducted according to Chinese standard GB/T 50080-2016 [34], as shown in Figure 3. The workability performance of coral concrete was classified according to Chinese standard GB50164-2011 [35], as shown in Table 6. Table 7 shows the original data measured in the test. In Figure 4, the curves show the relationship between concrete workability (slump $T_{\mathrm{i}}$ or dispersion $\left.K_{\mathrm{i}}\right)$ and fiber content $\left(m_{\mathrm{f}}\right)$. 


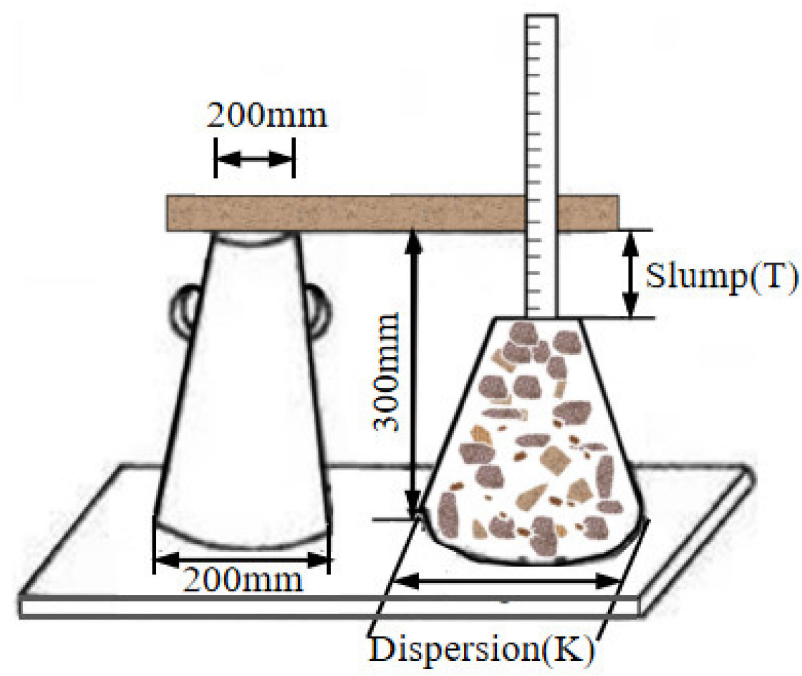

Figure 3. Slump and dispersion test method.

Table 6. Classification of workability (mm).

\begin{tabular}{ccccccc}
\hline Slump & $10-40$ & $50-90$ & $100-150$ & $160-210$ & $\geq 220$ & - \\
Grades & S1 & S2 & S3 & S4 & S5 & - \\
Dispersion & $\leq 340$ & $350-410$ & $420-480$ & $490-550$ & $560-620$ & $\geq 630$ \\
Grades & F1 & F2 & F3 & F4 & F5 & F6
\end{tabular}

Note: Slump and dispersion are quantitative indexes to measure the workability of concrete, and the greater the slump and dispersion, the better the workability. From S1 to S5 or from F1 to F6, the workability of concrete is getting better.

Table 7. Workability of coral concrete.

\begin{tabular}{ccccccccc}
\hline Groups & C25 & C30 & C35 & C40 & FC1 & FC2 & FC3 & FC4 \\
\hline Slump $\mathrm{T}_{\mathrm{i}} / \mathrm{mm}$ & 190 & 220 & 250 & 260 & 250 & 230 & 160 & 65 \\
Dispersion $\mathrm{K}_{\mathrm{i}} / \mathrm{mm}$ & 430 & 490 & 610 & 700 & 690 & 565 & 300 & 200 \\
Slump grade & S4 & S5 & S5 & S5 & S5 & S5 & S4 & S2 \\
Dispersion grade & F3 & F4 & F5 & F6 & F6 & F5 & F1 & F1 \\
\hline
\end{tabular}

Note: using the test method in Figure 3 , the slump value $T_{\mathrm{i}} \leq 300 \mathrm{~mm}$ and the dispersion value $K_{\mathrm{i}} \geq 200 \mathrm{~mm}$.

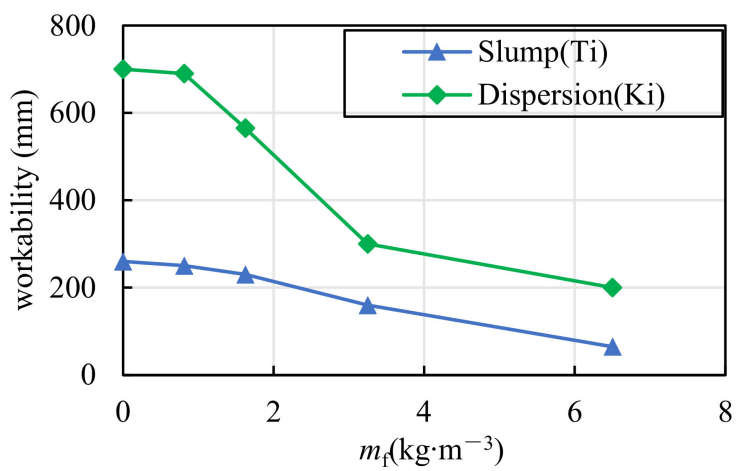

Figure 4. Effect of fiber content on concrete workability.

From Table 7, the workability of all plain coral concrete groups in this paper was very good, yet it can be seen that the slump and dispersion of coral concrete show a rapid downward trend indicating that the viscosity of coral concrete significantly increased with the increase of PVA fiber content (as shown in Figure 4). Moreover, when the PVA fiber content increased to $V_{\mathrm{f}}=6.5 \mathrm{~kg} / \mathrm{m}^{3}$, the coral concrete's fluidity was almost completely lost, and the slump value decreased to $65 \mathrm{~mm}$, only $25 \%$ of the reference group (C40). This 
is mainly due to the following two reasons. On the one hand, PVA fiber has a large specific surface area and good cement compatibility; with the increase of fiber content, more and more cement slurry is used to wrap the fiber, resulting in an increased cohesion of coral concrete. On the other hand, the disordered fibers scattered in the concrete form a bridging effect, which hinders the flow of coral concrete more with the increase of fiber content. As the slump of concrete shall not be less than $70 \mathrm{~mm}$ during construction in high temperature environment [36], it is suggested that the PVA fiber dosage of coral concrete should not exceed $5 \mathrm{~kg} / \mathrm{m}^{3}$ in marine environment construction. Besides, the dispersion of pumped concrete should not be less than $500 \mathrm{~mm}$ [35], and thus it is suggested that the PVA fiber dosage should not be more than $2.0 \mathrm{~kg} / \mathrm{m}^{3}$ if using pumping construction.

\subsubsection{Test Phenomenon}

During compression loading, almost all of the specimens shown obviously brittle failure. Most of the specimens began to appear obvious destructive cracks after bearing about $90 \%$ of the ultimate load. With the load approaching the peak load, the cracks spread rapidly and some of the concrete at the corners of the test specimens was torn into slag and dropped. Finally, the test specimen was destroyed immediately with a sound of cracking.

The typical failure of plain coral concrete specimen was mainly compression crushing, as shown in Figure 5, and some specimens were directly decomposed into several blocks by a few major cracks. Different from the crack propagation around the aggregate of ordinary concrete, all cracks in coral concrete specimens directly initiated and propagate through the coral aggregate, which indicated that the low strength and high porosity of coral aggregate leaded to the high brittleness of coral concrete. In addition, there are many visible holes of different sizes in the interior and surface of the coral concrete blocks with maximum diameter of about $2-3 \mathrm{~mm}$. This may be due to the high porosity of coral aggregate, which exhausts the gas in the internal pores during water absorption.

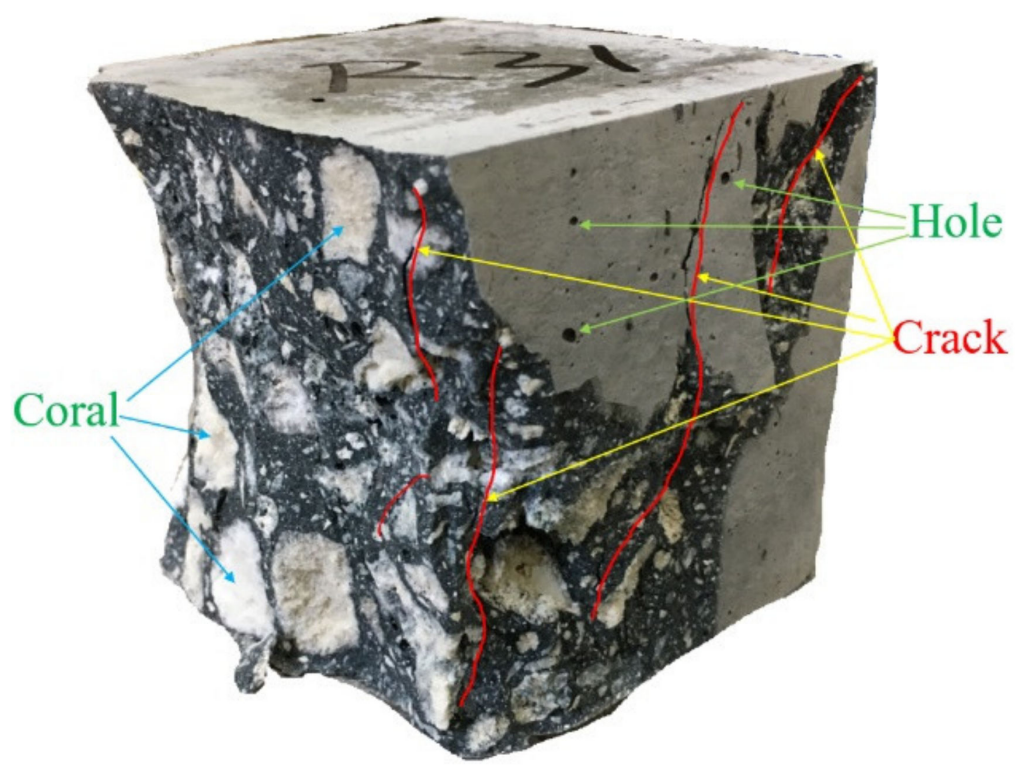

Figure 5. Typical failure modes of specimens in cube compression tests.

However, the brittleness of coral concrete was obviously improved by adding PVA fiber. Compared with the plain coral concrete group (C40), the integrity of the specimen with PVA fibers (FC1 to FC4) was better due to the bridging and toughening effect of PVA fiber, and the local chipping and peeling was also significantly reduced, some specimens still remained integrity after failure, as shown in Figure 6. 


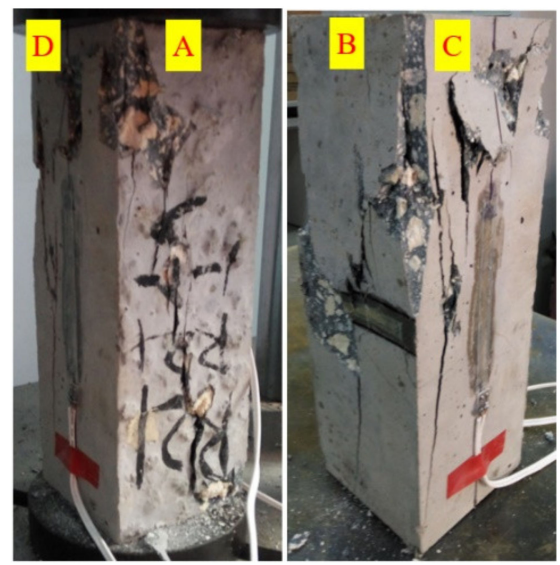

(a)

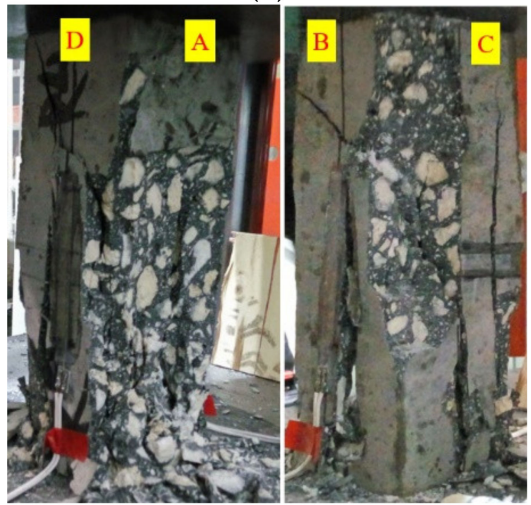

(d)

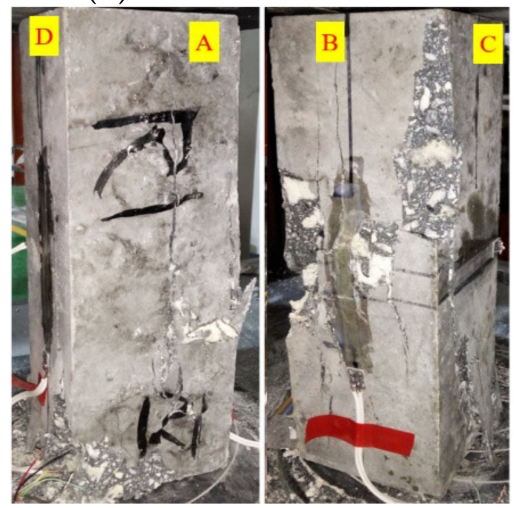

(g)

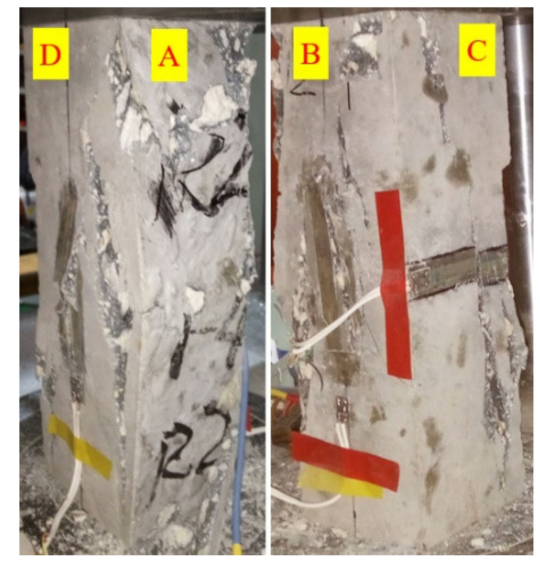

(b)

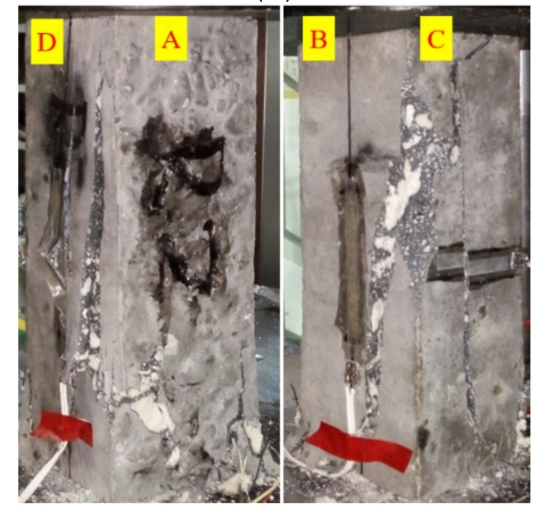

(e)

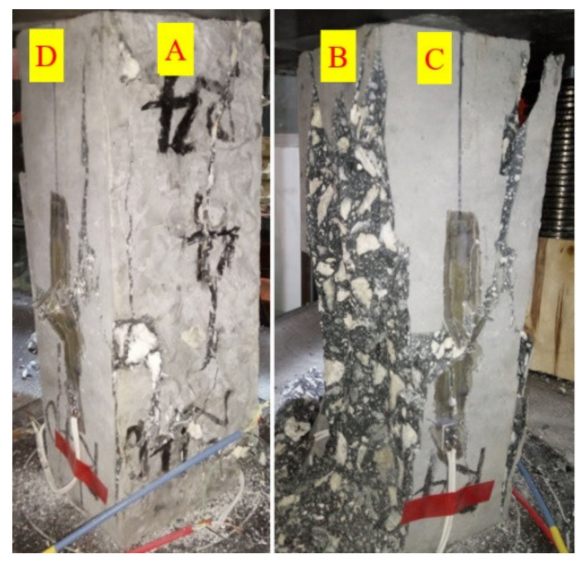

(c)

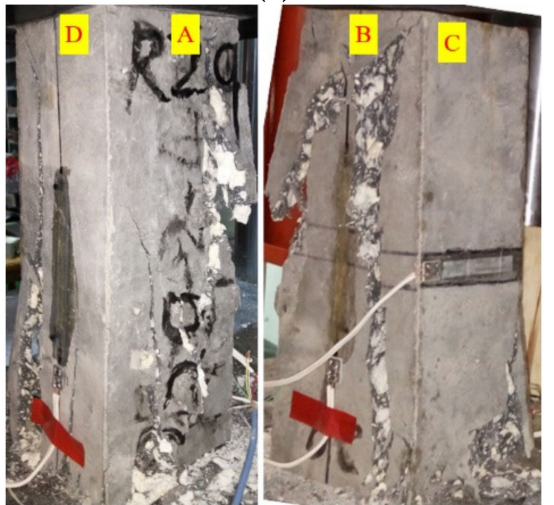

(f)

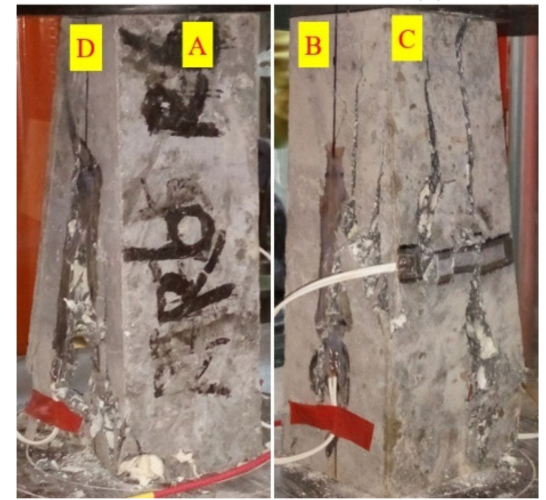

(h)

Figure 6. Failure modes of specimens in uniaxial compression stress-strain curve tests. (a) C25, $m_{\mathrm{f}}=0 \mathrm{~kg} \cdot \mathrm{m}^{-3} ;(\mathbf{b}) \mathrm{C} 30, m_{\mathrm{f}}=0 \mathrm{~kg} \cdot \mathrm{m}^{-3} ;$ (c) C35, $m_{\mathrm{f}}=0 \mathrm{~kg} \cdot \mathrm{m}^{-3} ;$ (d) C40, $m_{\mathrm{f}}=0 \mathrm{~kg} \cdot \mathrm{m}^{-3}$; (e) FC1, $m_{\mathrm{f}}=0.8125 \mathrm{~kg} \cdot \mathrm{m}^{-3} ;$ (f) FC2, $m_{\mathrm{f}}=1.625 \mathrm{~kg} \cdot \mathrm{m}^{-3} ;$ (g) FC $3, m_{\mathrm{f}}=3.25 \mathrm{~kg} \cdot \mathrm{m}^{-3} ;$ (h) FC4, $m_{\mathrm{f}}=6.5 \mathrm{~kg} \cdot \mathrm{m}^{-3}$.

\subsubsection{Mechanical Properties}

The mechanical properties of experimental specimens are summarized in Table 8 , and the measurement results are taken as the average of the three samples in each group. With comparison of specimens C40 and FC1 to FC4, it can be seen that adding an appropriate amount of PVA fiber can improve the compressive strength, peak strain, Poisson's ratio, and residual stress after crushing failure also increased significantly. Yet, the effect of PVA fiber content on the elastic modulus of coral concrete is less than $3.5 \%$. 
Table 8. Measured mechanical properties of coral concrete.

\begin{tabular}{ccccccccc}
\hline Groups & $\mathbf{m}_{\mathbf{f}}\left(\mathbf{k g} / \mathbf{m}^{3}\right)$ & $f_{\mathbf{c u}, 100,28 \mathbf{d}}(\mathbf{M P a})$ & $\sigma_{\mathbf{c r}}(\mathbf{M P a})$ & $\varepsilon_{\mathbf{c}}(\mu \varepsilon)$ & $E_{\mathbf{c}}(\mathbf{M P a})$ & $\mu$ & $\sigma_{\mathbf{r}}(\mathbf{M P a})$ & $w_{\mathbf{c}}\left(\mathbf{k g} / \mathbf{m}^{3}\right)$ \\
\hline C25 & 0 & 30.5 & 38.1 & 1754 & 24,960 & 0.229 & 8.7 & 2040 \\
C30 & 0 & 35.5 & 42.4 & 1874 & 26,179 & 0.224 & 7.6 & 2140 \\
C35 & 0 & 41.8 & 50.0 & 1940 & 28,886 & 0.242 & 4.8 & 2110 \\
C40 & 0 & 45.9 & 48.3 & 1889 & 28,542 & 0.242 & 3.9 & 2220 \\
FC1 & 0.8125 & 48.1 & 46.8 & 1856 & 28,093 & 0.237 & 7.5 & 2214 \\
FC2 & 1.625 & 51.2 & 49.8 & 1841 & 29,406 & 0.302 & 7.1 & 2193 \\
FC3 & 3.25 & 54.9 & 51.8 & 1977 & 28,488 & 0.286 & 6.8 & 2171 \\
FC4 & 6.5 & 50.3 & 49.5 & 2040 & 27,548 & 0.252 & 9.1 & 2150 \\
\hline
\end{tabular}

Note: $m_{\mathrm{f}}$ is fiber content; $f_{\mathrm{cu}, 100,28 \mathrm{~d}}$ is the cube compressive strength of concrete at 28 days with the size of $100 \mathrm{~mm} \times 100 \mathrm{~mm} \times 100 \mathrm{~mm} ; \sigma_{\mathrm{cr}}$ is the peak stress of concrete with the size of $100 \mathrm{~mm} \times 100 \mathrm{~mm} \times 300 \mathrm{~mm} ; \varepsilon_{\mathrm{c}}$ is peak strain; $E_{\mathrm{c}}$ is elastic modulus; $\mu$ is Poisson's ratio; $\sigma_{\mathrm{r}}$ is residual stress; $w_{\mathrm{c}}$ is apparent density.

In this paper, the slope of the linear segment between two points $\left(\left(\varepsilon_{1}, \sigma_{1}\right)\right.$ and $\left.\left(\varepsilon_{2}, \sigma_{2}\right)\right)$ of the ascent section of the longitudinal stress-strain curve was taken as the elastic modulus $E_{c}[37,38]$ of coral concrete, and this method is reasonable. The formula is as follows:

$$
E_{c}=\left(\sigma_{2}-\sigma_{1}\right) /\left(\varepsilon_{2}-\varepsilon_{1}\right)
$$

where $\sigma_{1}=0.2 \sigma_{\mathrm{cr}}, \sigma_{2}=0.4 \sigma_{\mathrm{cr}}, \varepsilon_{2}$ and $\varepsilon_{1}$ are the longitudinal strains corresponding to $\sigma_{2}$ and $\sigma_{1}$ on the stress-strain curve, respectively [38].

Poisson's ratio is defined as the absolute value of the ratio of the transverse strain to the longitudinal strain of the specimen [39]. In this paper, the ratio of the transverse strain to the longitudinal strain of two points $\left(\left(\varepsilon_{1}, \varepsilon_{t 1}, \sigma_{1}\right)\right.$ and $\left.\left(\varepsilon_{2}, \varepsilon_{t 2}, \sigma_{2}\right)\right)$ corresponding to $E_{c}$ is taken as Poisson's ratio, and the formula is as follows:

$$
\mu=\left(\varepsilon_{t 2}-\varepsilon_{t 1}\right) /\left(\varepsilon_{2}-\varepsilon_{1}\right)
$$

where $\varepsilon_{\mathrm{t} 1}\left(\varepsilon_{\mathrm{t} 2}\right)$ and $\varepsilon_{1}\left(\varepsilon_{2}\right)$ are the transverse strain and longitudinal strain corresponding to the stress of $0.2 \sigma_{\mathrm{cr}}$ and $0.4 \sigma_{\mathrm{cr}}$, respectively, on the ascend stage of the uniaxial compression stress-strain curve.

\subsection{Discussions on Uniaxial Compression Stress-Strain Curves}

\subsubsection{Test Results}

According to Equations (3) and (4), the measured load and longitudinal displacement were converted into stress $\sigma$ and strain $\varepsilon$.

$$
\begin{gathered}
\sigma=P / A \\
\varepsilon= \begin{cases}\left(\varepsilon_{L}+\varepsilon_{R}\right) / 2 & \left(\sigma \leq \sigma_{\mathrm{cr}}\right) \\
\Delta L / L & \left(\sigma>\sigma_{\mathrm{cr}}\right)\end{cases}
\end{gathered}
$$

where $\sigma$ is stress of concrete specimen $(\mathrm{MPa}) ; P$ is axial pressure $(\mathrm{N}) ; A$ is concrete specimen compression area $\left(\mathrm{mm}^{2}\right) ; \varepsilon$ is longitudinal strain of concrete specimen; $L$ is the longitudinal displacement $(\mathrm{mm}) ; \Delta L$ is longitudinal deformation $(\mathrm{mm}) ; \varepsilon_{L}, \varepsilon_{R}$ are longitudinal strains measured by the longitudinal strain gauges on the $B$ side and D side of the specimen (see Figure $2 b$ ) before loading to the ultimate load.

In order to analyze the stress-strain curve and toughness index accurately, the author normalized the measured data as follows:

Firstly, the stress values and the strain values of the stress-strain curve were divided by the peak stress and peak strain, respectively, as follows:

$$
\begin{aligned}
& y=\sigma / \sigma_{c r} \\
& x=\varepsilon / \varepsilon_{c r}
\end{aligned}
$$


where $\sigma_{\mathrm{cr}}$ is peak stress $(\mathrm{MPa}) ; \varepsilon_{\mathrm{cr}}$ is peak strain.

Secondly, on the basis of the equal or close strain values $\left(x_{1 i} \approx x_{2 i} \approx x_{3 i}\right)$, calculating the weighted average of the stress values of three specimens from the same group (the weighting coefficient is $1 / 3)$, i.e., as follows:

$$
\begin{aligned}
& x_{i}=\frac{x_{1 i}+x_{2 i}+x_{3 i}}{3} \\
& y_{i}=\frac{y_{1 i}+y_{2 i}+y_{3 i}}{3}
\end{aligned}
$$

where $x_{1 i}, x_{2 i}, x_{3 i}$ are the relative strain values (dimensionless) of three samples in the same group respectively, $y_{1 i}, y_{2 i}, y_{3 i}$ are the relative stress values (dimensionless) corresponding to $x_{1 i}, x_{2 i}, x_{3 i}$, respectively.

In order to get accurate and effective normalized stress-strain curve, it is necessary to pay attention to the continuous transition around the peak point (E) and residual point (R) to ensure the consistency with the original curve shapes, taking group 5 as an example, shown in Figure 7.

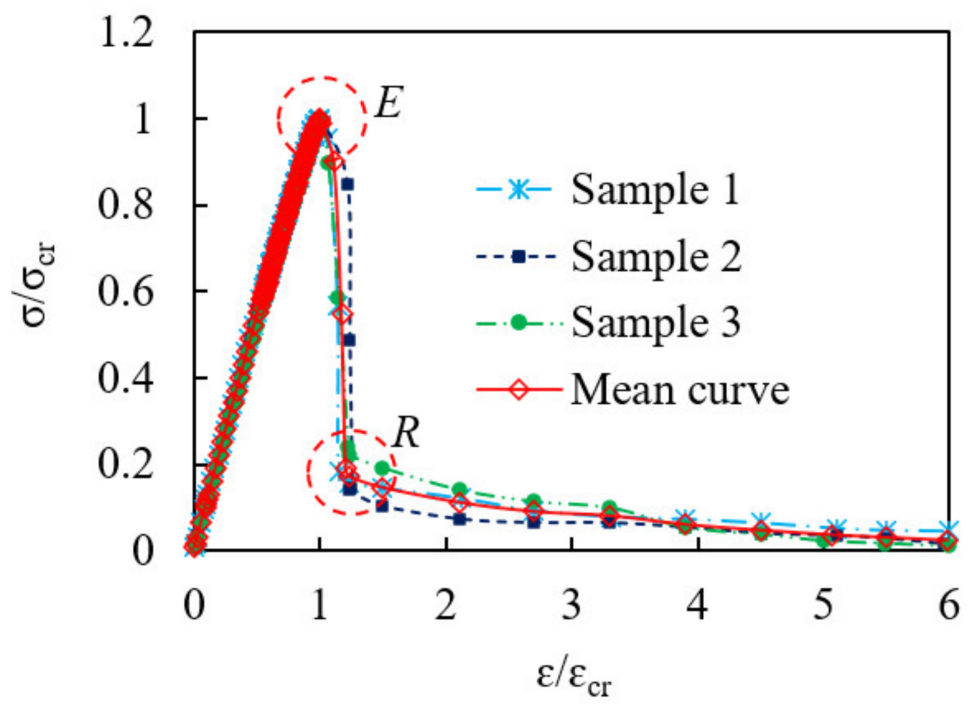

Figure 7. Standardization of stress-strain curve (CF4).

Finally, according to the above steps, the normalized curves of all test groups were obtained, and the stress and strain values (dimensionless) of the normalized stress-strain curves were multiplied by the average peak stress and average peak strain of the same group, respectively, so as to obtain the average stress-strain curves of each group, as shown in Figure 8.

As shown in Figure 8, before $90 \%$ of the peak stress, the slope is constant, indicating that the strain increases linearly with the stress. As the stress approaches $90 \%$ of the peak stress, some visible cracks begin to appear on the surface of concrete and then develops rapidly. Afterwards, with increasing the stress up to ultimate stress, the curves start to clearly deviate from the straight line. When the stress exceeds the ultimate stress, the stress decreases sharply and then the specimens are crushed rapidly. As a result, only a few data points in the declining stage of curves could be collected due to the rapid failure process.

With an increase of concrete strength, the slope of stress-strain relationship increases correspondingly, indicating the elastic modulus of coral concrete increases, and the peak strain also increases, as shown in Figure 8a. However, the residual stress generally decreases with increasing concrete strength, as shown in Figure 8a and Table 8. From the normalized stress-strain relationship in Figure 8b, it can be seen that the curves of coral concrete with different strengths almost coincide in the linear part before $90 \%$ of the peak stress, thus 
it can be concluded that the elastic modulus of coral concrete may have an approximate linear relationship with the strength.

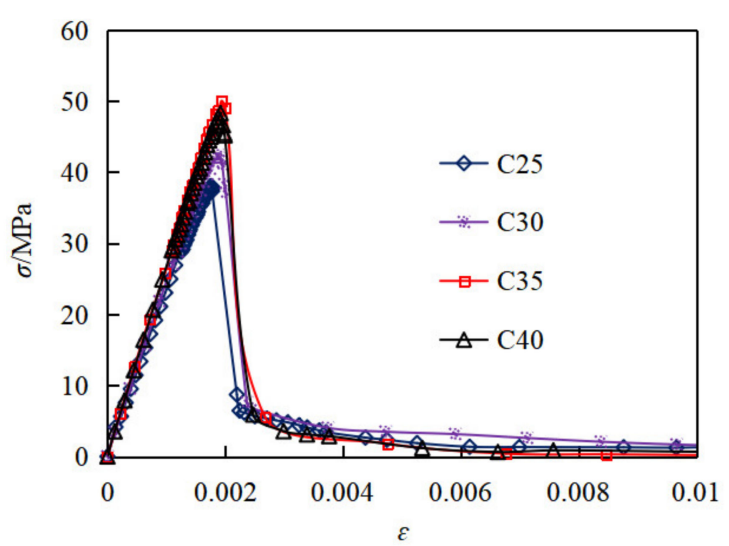

(a)

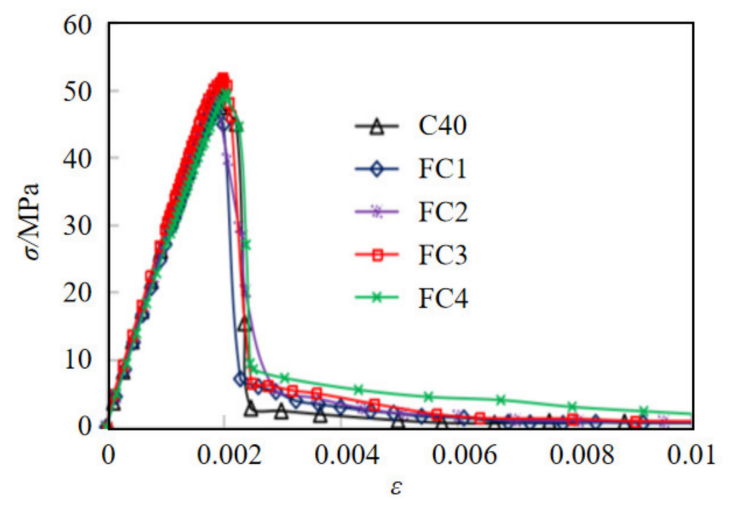

(c)

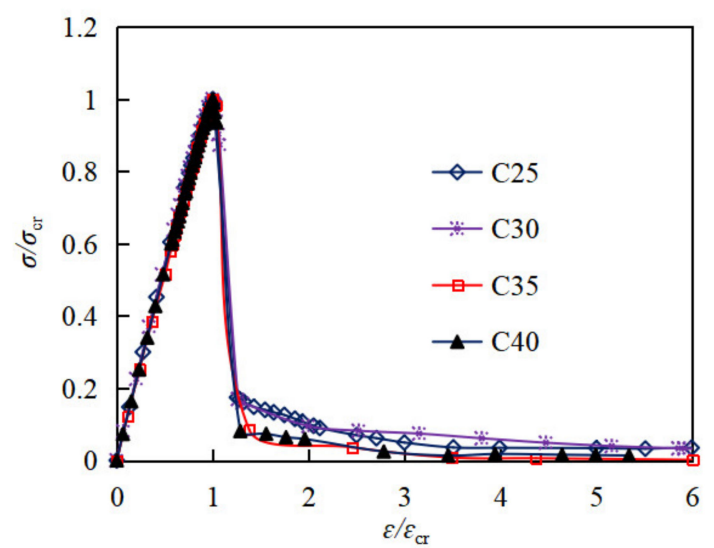

(b)

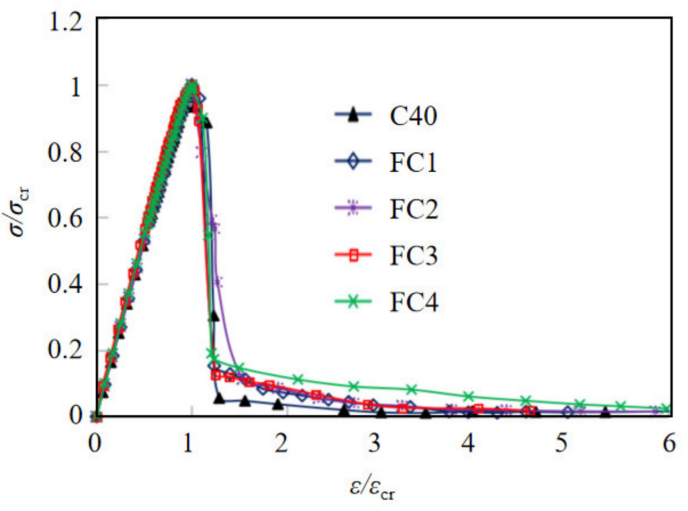

(d)

Figure 8. Comparative stress-strain relationship for coral concrete with different strengths and fiber content. (a) stress-strain relationship for coral concrete with different strengths, (b) normalized stress-strain relationship for coral concrete with different strengths (dimensionless), (c) stress-strain relationship for coral concrete with different fiber content, (d) normalized stress-strain relationship for coral concrete with different fiber content (dimensionless).

As can be seen from Figure 8c and Table 8, compared with the control group (C40), when the content of PVA fiber was $0.8125 \mathrm{~kg} / \mathrm{m}^{3}, 1.625 \mathrm{~kg} / \mathrm{m}^{3}, 3.25 \mathrm{~kg} / \mathrm{m}^{3}, 6.5 \mathrm{~kg} / \mathrm{m}^{3}$, the peak stress of coral concrete increased by $-3.1 \%, 3.1 \%, 7.3 \%, 2.5 \%$, the peak strain increased by $-1.7 \%,-2.5 \%, 4.7 \%, 8.0 \%$, the residual stress after failure increased by $27.1 \%, 20.3 \%, 25.4 \%, 66.1 \%$, and the Poisson's ratio increased by $6.7 \%, 23.8 \%, 25.8 \%, 3.3 \%$, respectively, indicating that the addition of an appropriate amount of PVA fiber had a positive toughening effect. However, the initial elastic modulus was rarely influenced by fiber content before $50 \%$ of the peak stress. In addition, the shape and the feature point of the normalized stress-strain curves of the coral concrete with different fiber content had a minor difference.

\subsubsection{Toughness Index}

Toughness is an important index to evaluate the deformation ability of materials or structures after reaching the ultimate load [40]. Referring to the evaluation method of concrete toughness index [41] and some suggestions from literature [42], the paper used the area parameters under the stress-strain curve of uniaxial compression (normalized) to describe the toughness, with the peak point $\left(\sigma_{c r}, \varepsilon_{c r}\right)$ as the first feature point and the 
$3 \varepsilon_{c r}$ point as the second characteristic point, as shown in Figure 9. The formulas are given as follows:

$$
\begin{gathered}
\delta=\frac{A_{1}+A_{2}}{A_{1}}=\frac{\int_{0}^{3 \varepsilon_{c r}} \sigma d \varepsilon}{\int_{0}^{\varepsilon_{c r}} \sigma d \varepsilon}=\frac{\left(\sigma_{c r} \times \varepsilon_{c r}\right) \int_{0}^{3} y d \varepsilon}{\left(\sigma_{c r} \times \varepsilon_{c r}\right) \int_{0}^{1} y d \varepsilon}=\frac{\int_{0}^{3} y d \varepsilon}{\int_{0}^{1} y d \varepsilon} \\
\beta=\frac{A_{1}}{A_{2}}=\frac{\int_{0}^{\varepsilon_{c r}} \sigma d \varepsilon}{\int_{\varepsilon_{c r}}^{3 \varepsilon_{c r}} \sigma d \varepsilon}=\frac{\left(\sigma_{c r} \times \varepsilon_{c r}\right) \int_{0}^{1} y d \varepsilon}{\left(\sigma_{c r} \times \varepsilon_{c r}\right) \int_{1}^{3} y d \varepsilon}=\frac{\int_{0}^{1} y d \varepsilon}{\int_{1}^{3} y d \varepsilon}=\frac{1}{\delta-1}
\end{gathered}
$$

where $\delta$ is the toughness index of coral concrete; $\beta$ is the brittleness index of coral concrete; $A_{1}$ is the area enclosed by the stress-strain curve in the strain $\left(0-\varepsilon_{c r}\right)$ interval, which represents the energy density absorbed before concrete failure; $A_{2}$ is the area enclosed by the stress-strain curve in the strain $\left(\varepsilon_{c r}, 3 \varepsilon_{c r}\right)$ interval, which represents the energy density released during the concrete failure process.

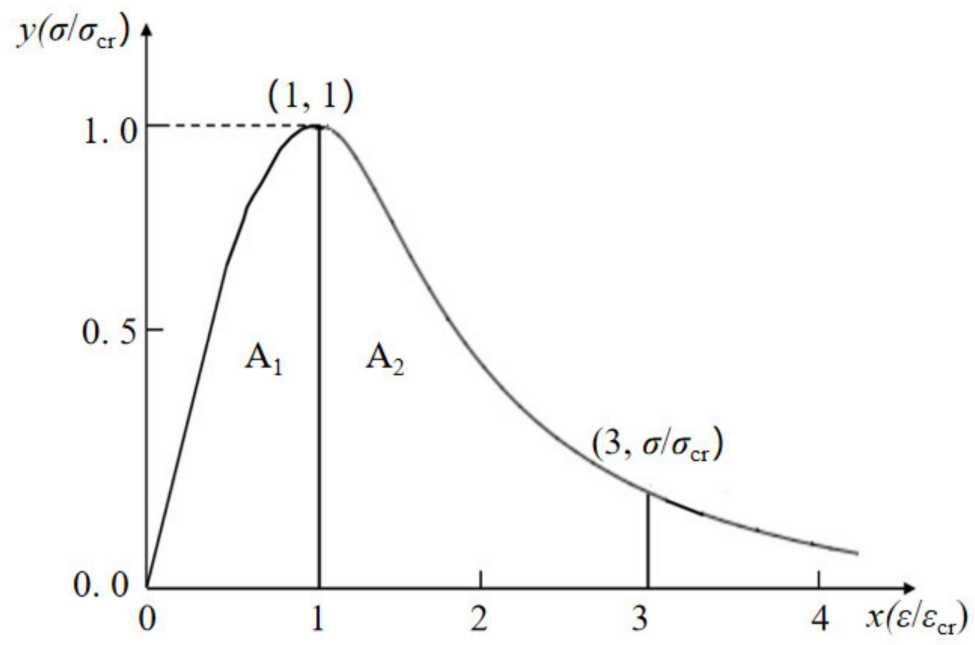

Figure 9. Feature points of toughness index.

As shown in Figure 10, with increase of concrete strength, the area parameter $A_{2}$ decreases obviously while the area parameter $A_{1}$ rarely changes. Thus, the corresponding toughness index $\delta$ decreases and brittleness index $\beta$ increases.

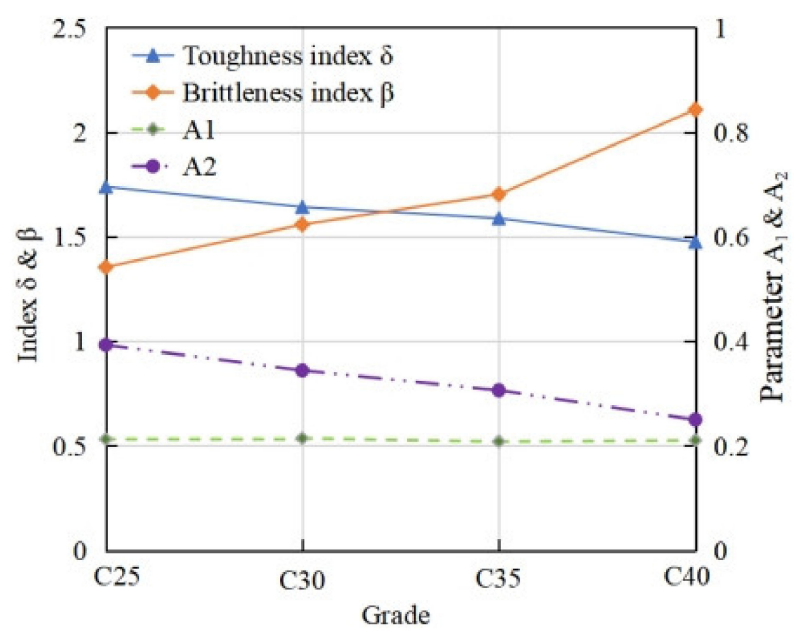

Figure 10. Toughness of coral concrete with different strengths.

As shown in Figure 11, the area parameter $A_{1}$ of fiber reinforced coral concrete increased slightly, but the influence of different fiber content is not obvious among the different specimen fiber contents. However, the fiber has significant influence on area parameter $A_{2}$. Compared with group C40 without fiber, when the fiber content is $0.8125 \mathrm{~kg} / \mathrm{m}^{3}$, 
$1.625 \mathrm{~kg} / \mathrm{m}^{3}, 3.25 \mathrm{~kg} / \mathrm{m}^{3}$ and $6.5 \mathrm{~kg} / \mathrm{m}^{3}$, the parameter $A_{2}$ increases by $23.6 \%, 37.9 \%, 54.0 \%$ and $49.4 \%$, respectively, and the toughness index $\delta$ increased by $7.5 \%, 12.3 \%, 15.0 \%$ and $14.5 \%$, respectively. Correspondingly, the brittleness index $\beta$ declined by $18.9 \%, 27.6 \%$, $31.8 \%$ and $31.1 \%$, respectively, which shows that the ductility of the coral concrete is effectively improved by adding fiber.

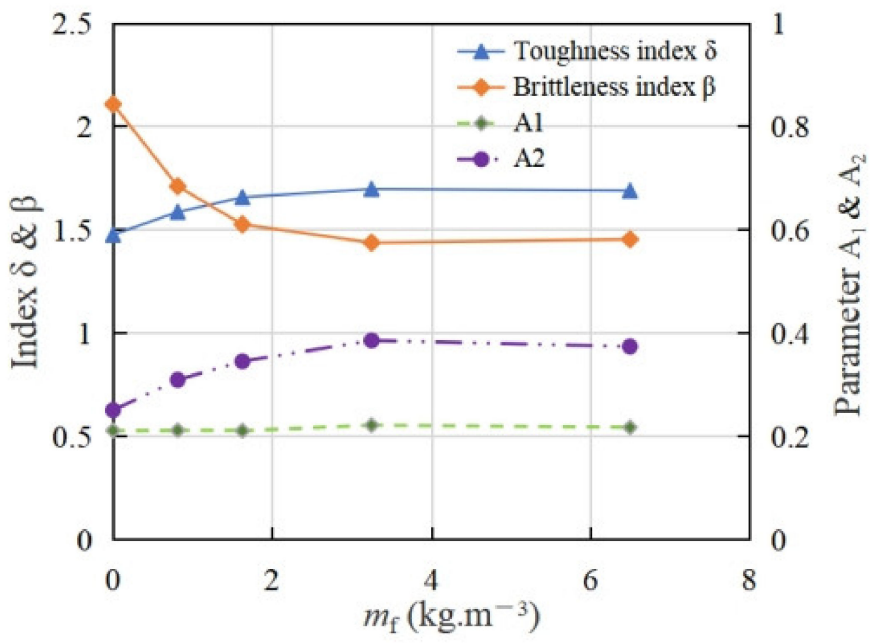

Figure 11. Toughness of coral concrete with different fiber contents.

\subsubsection{Numerical Modeling}

The existing literatures show that there is no unified conclusion about the expression of the uniaxial compression stress-strain curve of coral concrete. Based on the existing concrete constitutive models and the test data, there is no unified constitutive models to describe the compression behavior of coral concrete. Considering the significant differences in the stress-strain curve between the ascending and declining stages of coral concrete, piecewise functions are used to describe the curve.

In this paper, according to the curve characteristics of coral concrete, three models with different mathematical presentations are selected to calculate the ascending and declining stages of the curve, as shown in Table 9, and the accuracy of different models is shown in Figure $12\left(R_{a}^{2}\right.$ and $\left.R_{d}^{2}\right)$ represent the fitting degree of the model in the ascending stages and descending stages, respectively).

Table 9. Different models of stress-strain curve equation.

\begin{tabular}{cccc}
\hline Section & Numbers & Mathematical Model & Proposer/Literature \\
\hline \multirow{3}{*}{ Ascending stage } & model 1 & $y=a x+(3-2 a) x^{2}+(a-2) x^{3}$ & Guo [43] \\
& model 2 & $y=\frac{(a+1) x}{\left(a+x^{a+1}\right)}$ & Yang [44] \\
& model 3 & $y=x e^{a(1-x)}$ & Sahlin [45] modified \\
\hline \multirow{3}{*}{ Declining stage } & model 1 & $y=\frac{x}{b(x-1)^{c}+x}$ & Zhao [46] \\
& model 2 & $y=\frac{x}{b(x-1)^{2}+x}$ & GB50010-2010 [47] \\
& model 3 & $y=\frac{x}{b(x-1)+x}$ & Da [27]
\end{tabular}

Notes: $x=\varepsilon_{\mathrm{c}} / \varepsilon_{\mathrm{cr}}, y=\sigma_{\mathrm{c}} / \sigma_{\mathrm{cr}}, \sigma_{\mathrm{cr}}, \varepsilon_{\mathrm{cr}}$ is the peak stress and peak strain; $a, b$ and $c$ are the undetermined parameters of the model.

As can be seen from Figure 12, in the ascending stage, the predicted results of model 2 and model 3 are in good agreement with the experimental data $\left(R_{a}^{2} \geq 0.99\right)$, while in the descending stage, the predicted results of model 1 and model 2 are in good agreement with the experimental data $\left(R_{d}^{2} \geq 0.95\right)$. Considering the coincidence with experimental curve and characteristic points of stress-strain curve, generally model 2 presents better results. Thus, the constitutive relationship of plain and PVA fiber-reinforced coral concrete can be recommend by the piecewise function model as the following equations, of which 
Equation (11) proposed by Yang [44] can be used to describe the ascending stage, and Equation (12) suggested by GB50010-2010 [47] can be used to describe the declining stage.

$$
\begin{gathered}
y=\frac{(a+1) x}{a+x^{a+1}} \\
y=\frac{x}{b(x-1)^{2}+x}
\end{gathered}
$$

\subsubsection{Determination of Parameters and Model Validation}

As important parameters of concrete, elastic modulus and peak strain are both critical parameters to reflect uniaxial compression behavior. Several studies have identified that there are many factors affecting the elastic modulus and peak strain of concrete, such as concrete strength and aggregate type [44,48].

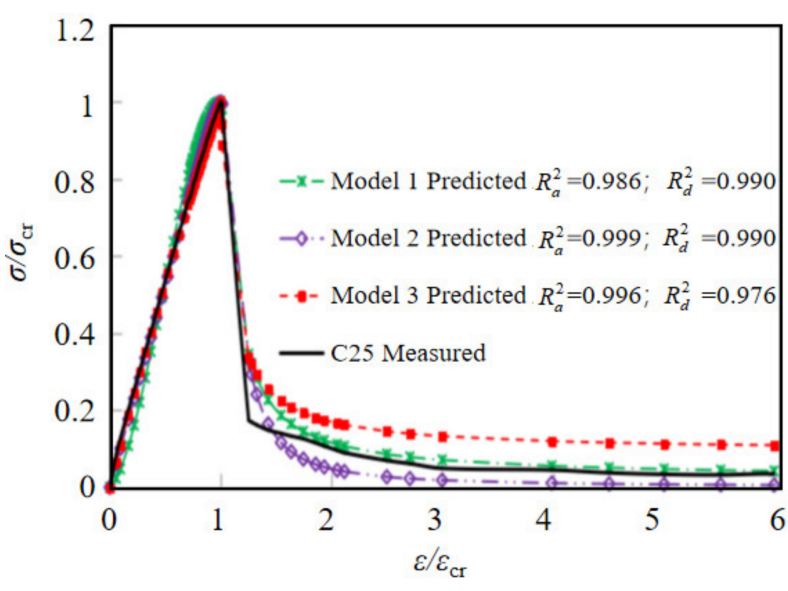

(a)

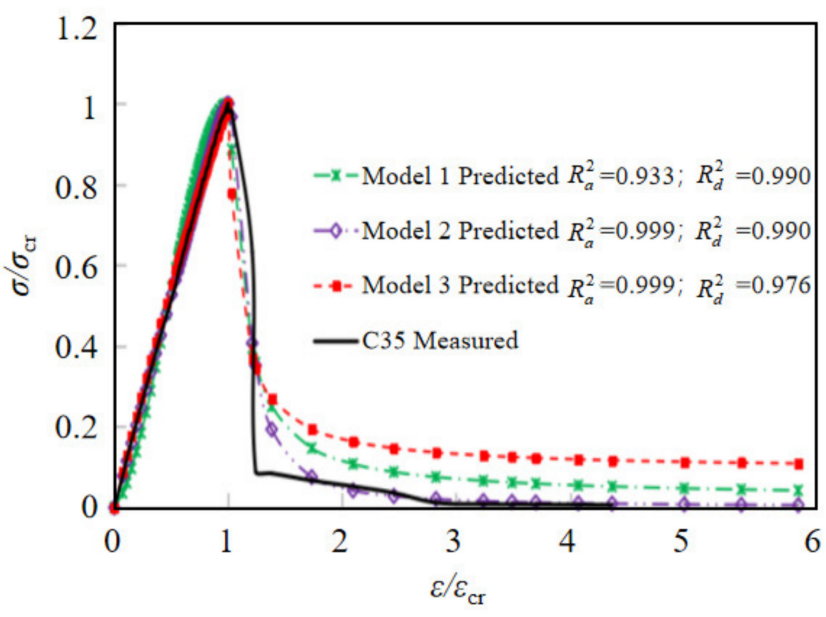

(c)

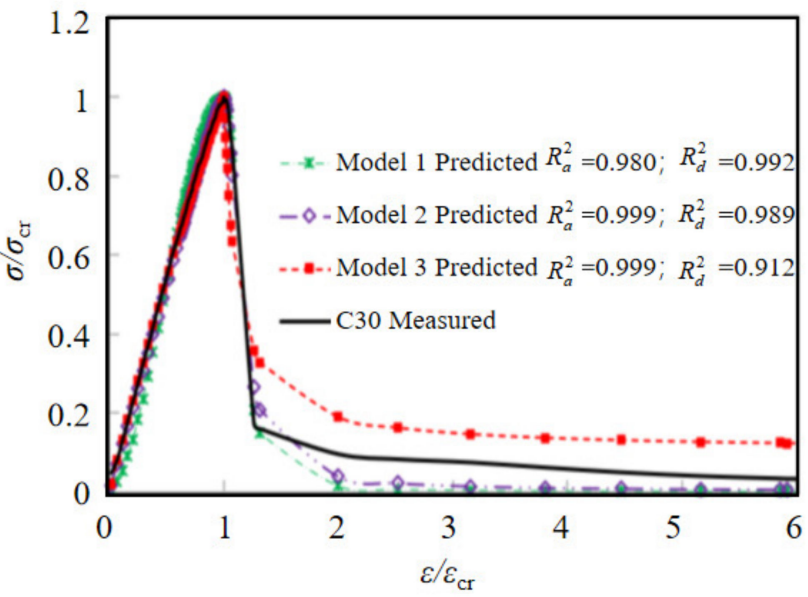

(b)

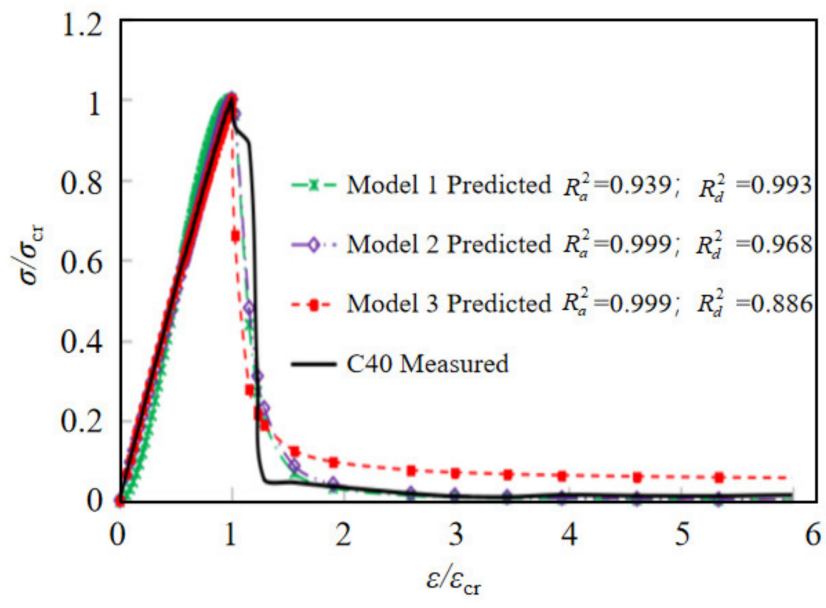

(d)

Figure 12. Cont. 


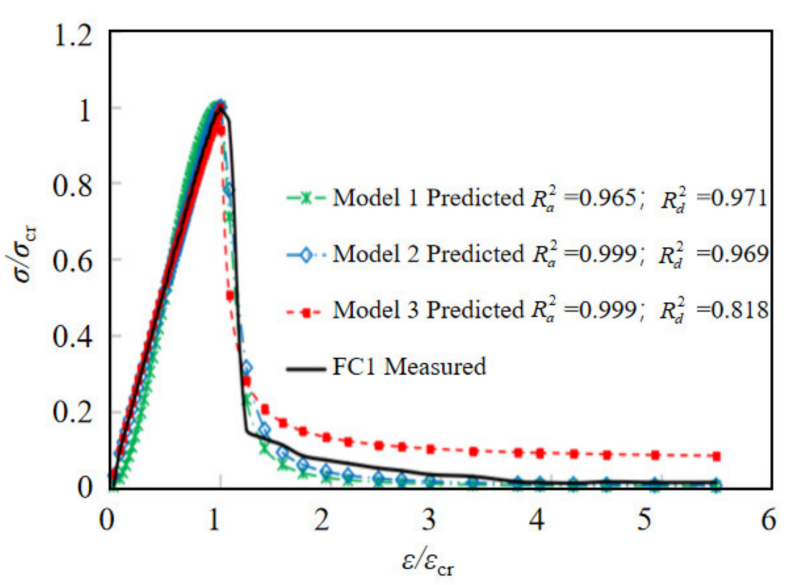

(e)

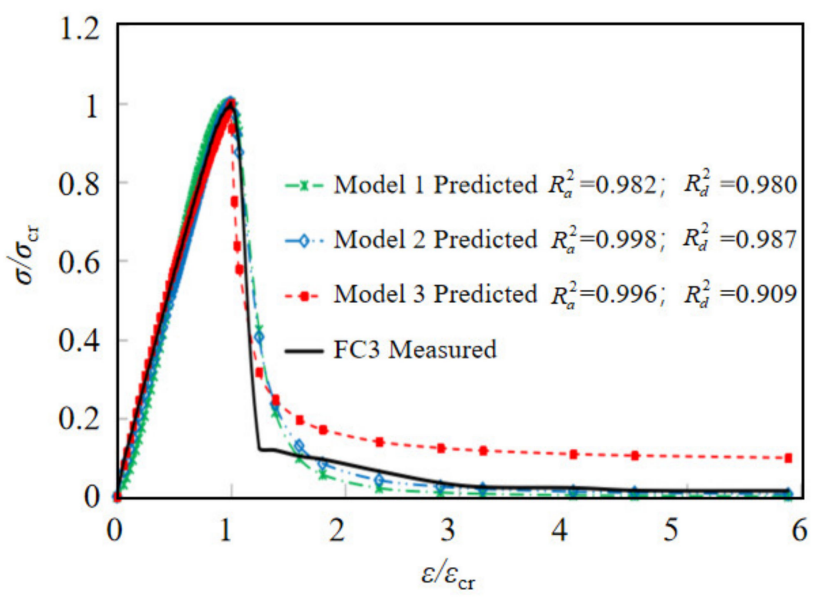

(g)

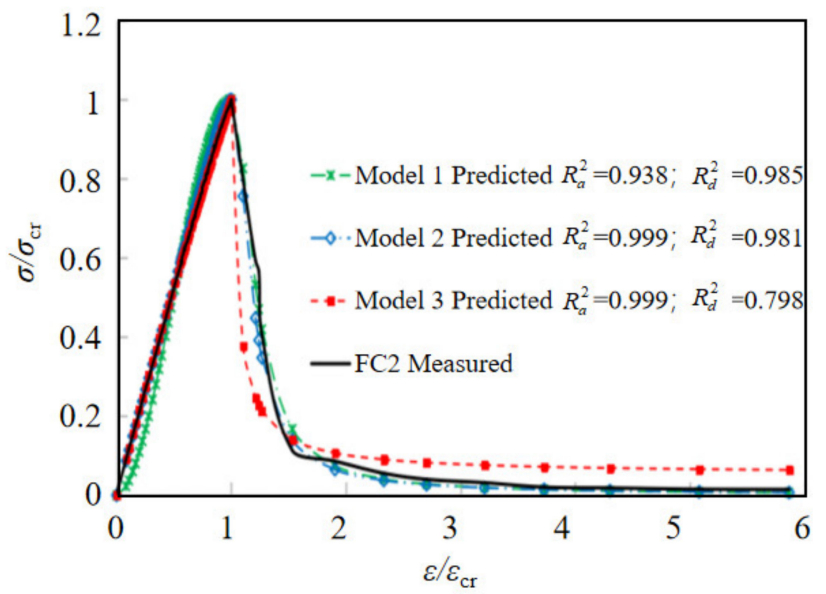

(f)

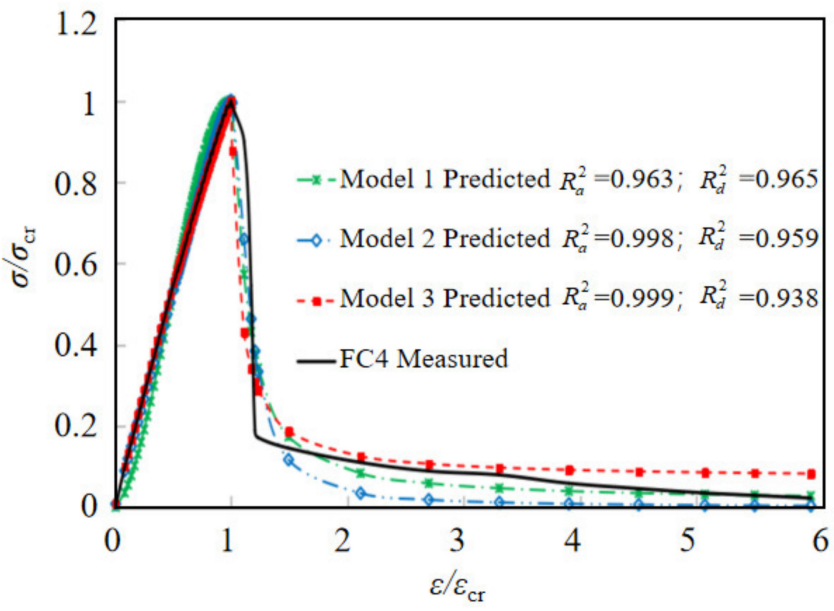

(h)

Figure 12. The fitting effect of stress-strain curves using different models. (a) C25, (b) C30, (c) C35, (d) C40, (e) FC1, (f) FC2, (g) FC3, (h) FC4.

As shown in Table 8 and discussed in Section 3.1.2 of this paper, the fiber has rarely influence on the elastic modulus of concrete. As shown in Figure 8a, the elastic modulus and the peak strain of coral concrete increases with an increase of concrete strength. Previous research has reported that the type of aggregate will also affect the elastic modulus of concrete, which is reflected by concrete density $w_{\mathrm{C}}$ [44]. Thus, based on the test data of plain and fiber-reinforced coral concrete from this research and previous literatures, the prediction approach of coral concrete elastic modulus $E_{\mathrm{c}}$ can be established with the prism compression strength $f_{\mathrm{c}}$ and concrete density $w_{\mathrm{c}}$ by regression analysis with 78 specimen test data, as shown in Equation (13). The validation of the prediction approach for elastic modulus is shown in Figure 13, with the determination coefficient $R^{2}=0.799$. As shown in Figure $8 \mathrm{a}, \mathrm{c}$, the peak strain of coral concrete increases to some extent with increasing prism compression strength, and also increases obviously with increasing PVA fiber content. By regression analysis with 42 specimen test data, the prediction approach of peak strain for coral concrete can be established with the prism compression strength $f_{\mathrm{c}}$, elastic modulus $E_{\mathrm{c}}$ and fiber content $m_{\mathrm{f}}$. The validation of the prediction approach for peak strain is shown in Figure 14, with the determination coefficient $R^{2}=0.661$. Among the experimental specimens, $f_{\mathrm{c}}$ representing the prism compression strength varies from $25 \mathrm{MPa}$ to $75 \mathrm{MPa}$, 
$w_{\mathrm{c}}$ representing the concrete density varies from $1900 \mathrm{~kg} / \mathrm{m}^{3}$ to $2300 \mathrm{~kg} / \mathrm{m}^{3}$, and $m_{\mathrm{f}}$ representing the fiber content varies from $1 \mathrm{~kg} / \mathrm{m}^{3}$ to $6.2 \mathrm{~kg} / \mathrm{m}^{3}$.

$$
\begin{gathered}
E_{c}=8220\left(f_{c}\right)^{1 / 3}\left(w_{c} / 2300\right)^{0.862} \quad\left(R^{2}=0.799\right) \\
\varepsilon_{c r}=0.00108 \exp \left(319 f_{\mathrm{c}} / E_{\mathrm{c}}\right)\left(0.0025 \mathrm{~m}_{\mathrm{f}}^{2}-0.0082 \mathrm{~m}_{\mathrm{f}}+1\right) \quad\left(R^{2}=0.661\right)
\end{gathered}
$$

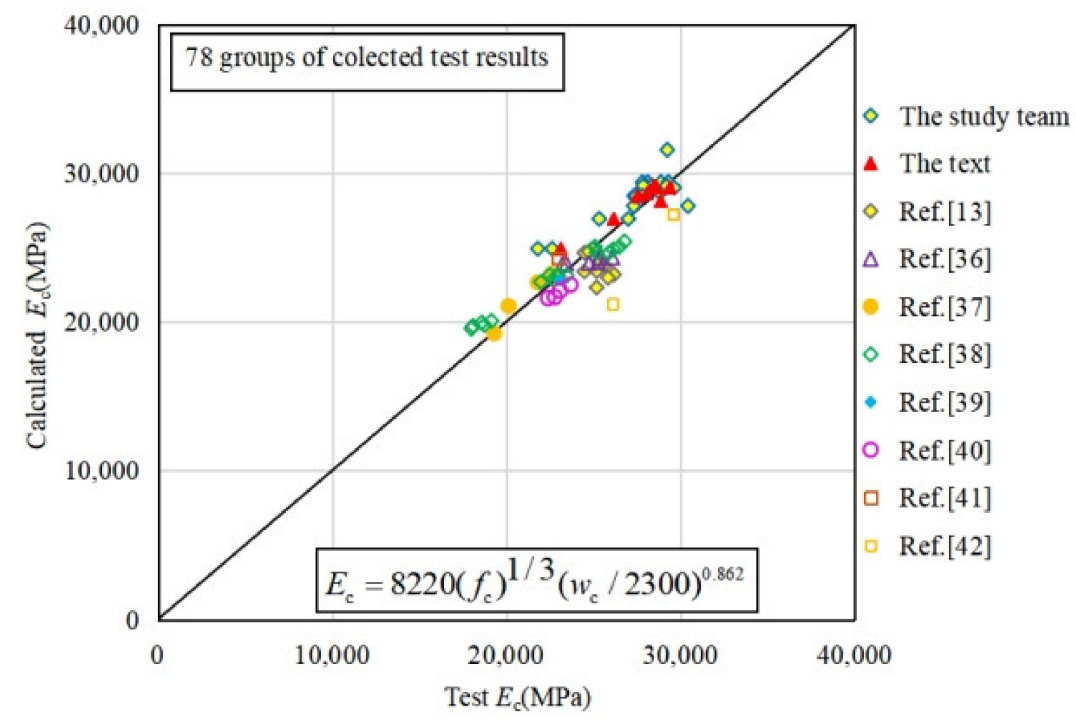

Figure 13. Comparison of test values and predicted values of elastic modulus.

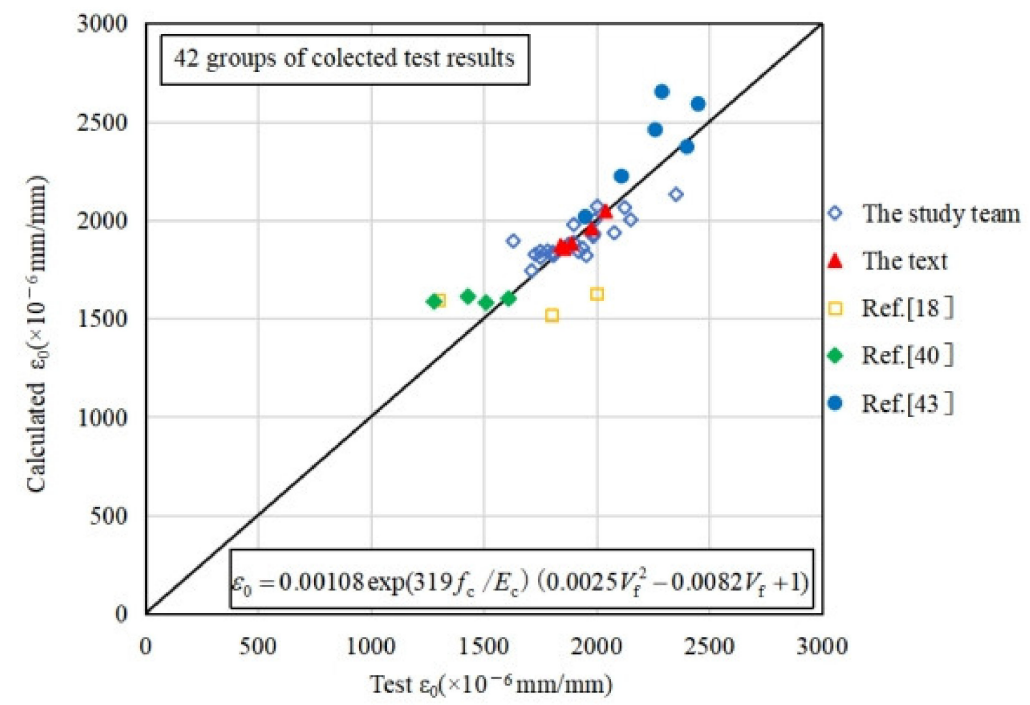

Figure 14. Comparison of test values and predicted values of peak strain.

As discussed above, Equations (11) and (12) are used to describe the uniaxial compression stress-strain behavior of plain and PVA fiber-reinforced coral concrete. Herein, the critical undetermined parameters $a$ and $b$ in Equations (11) and (12) needs to be determined for plain and PVA fiber reinforced coral concrete.

As can be seen from Figure 15, the smaller the value of parameter $a$, the plumper the curve, and the lower the strain growth rate of concrete in the loading process, then the more energy it would absorb. Similarly, the smaller the value of parameter $b$, the plumper the curve, the lower the slope of the curve in the unloading process, the slower the failure process, and the more energy released, which means the ductility of the coral concrete will 
be better. According to Figures 8 and 15, it can be concluded that $a$ and $b$ should decrease with increasing coral concrete strength and increase with increasing fiber content.

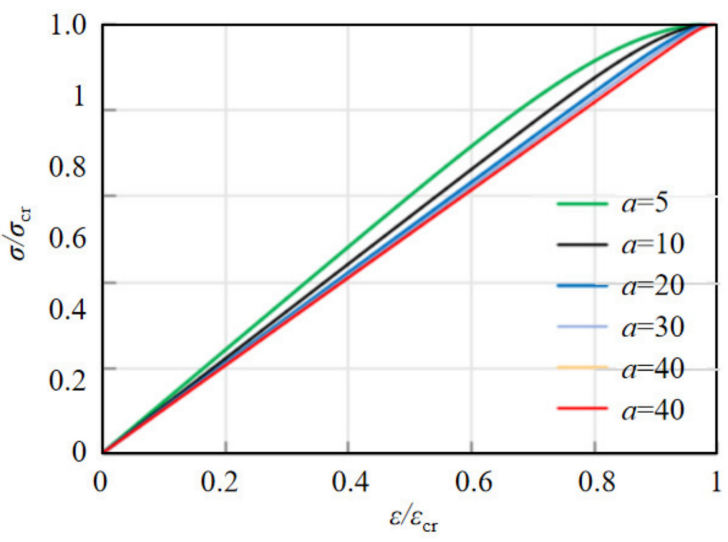

(a)

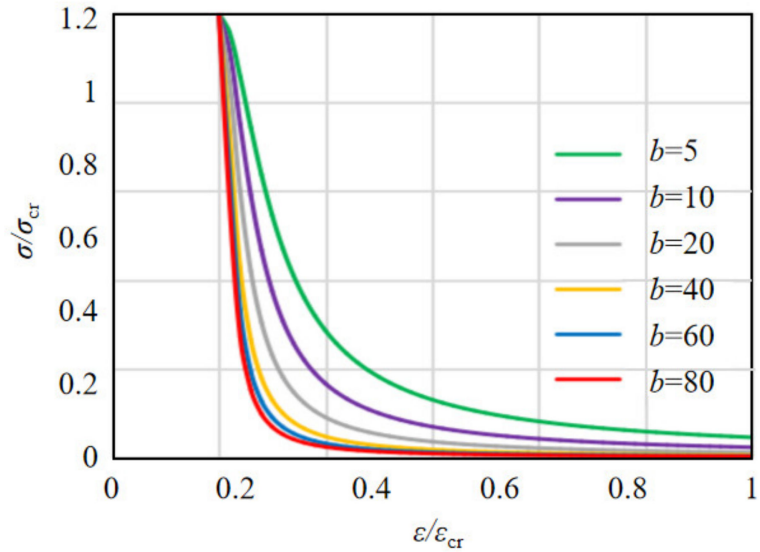

(b)

Figure 15. Effect of parameters " $a$ " and " $b$ " on $\sigma / \sigma_{\mathrm{cr}}-\varepsilon / \varepsilon_{\mathrm{cr}}$ curve. (a) Ascending stage, (b) Descent stage.

As shown in Figure 16, the test data of the specimens of coral concrete are collected and calculated to obtain the relationship between model parameters $a$ or $b$ and the toughness index of coral concrete. The results show that with the decrease of parameter $a$ or $b$, the toughness parameters $A_{1}$ or $A_{2}$ tends to increase, simultaneously, $A_{2}$ or " $A_{1}+A_{2}$ " is positively correlated with the toughness index $\delta$, and negatively correlated with the brittleness index $\beta$, but the relationship between $A_{1}$ and $\delta$ or $\beta$ is not obvious. That is to say, with smaller parameters $a$ and $b$, the corresponding $A_{1}$ and $A_{2}$ will become larger, and " $A_{1}+A_{2}$ " will also become larger, resulting in a larger toughness index $\delta$ and lower brittleness index $\beta$, indicating better deformation performance of the coral concrete. This is consistent with the conclusion of Figure 15. The results above from Figures 15 and 16 show that the model parameters are related to the shape of the stress-strain curve.

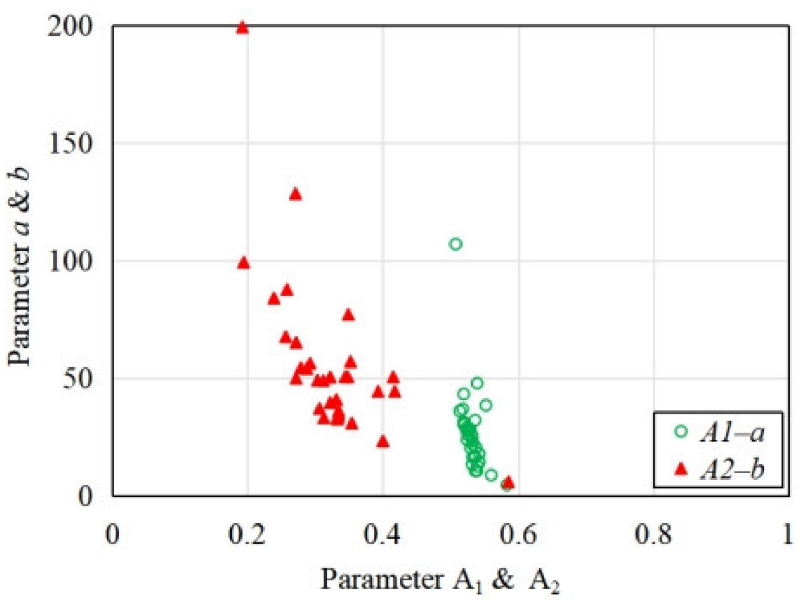

(a)

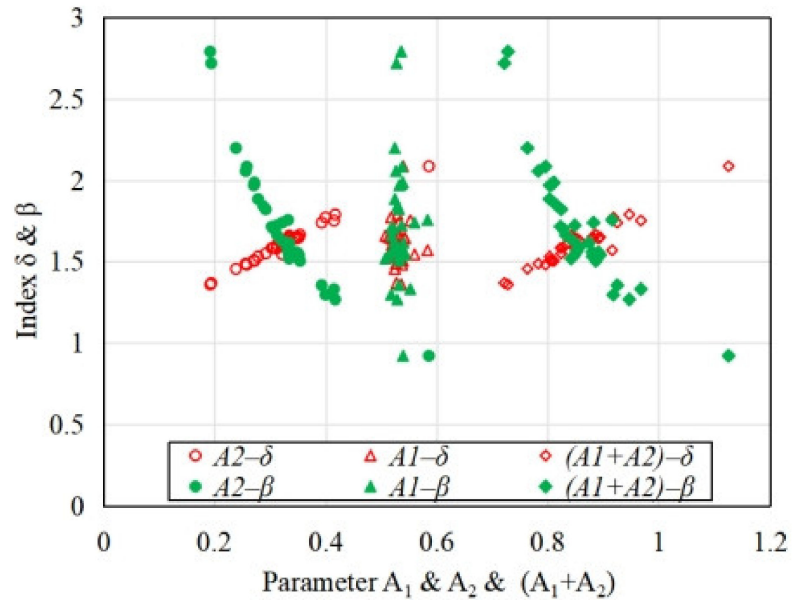

(b)

Figure 16. The relationship between model parameters and the toughness index of coral concrete. (a) The relationship between $a$ and $A_{1}$ (or $b$ and $A_{2}$ ), (b) The relationship between $\delta, \beta$ and $A_{1}, A_{2}$, " $A_{1}+A_{2}$ ".

Based on the analysis of the calculated results of the proposed model and the experimental data, the parameters $a$ and $b$ are both related to the fiber content and the compressive strength of coral concrete. In addition, the parameter $a$ influencing the curve shape of 
the ascending stage may be also related to the elastic modulus $E_{\mathrm{c}}$ and peak strain $\varepsilon_{\mathrm{cr}}$ of coral concrete because they also influenced the curve shape, the toughness index $\delta$ and the brittleness index $\beta$. Therefore, the critical undetermined parameters $a$ and $b$ in Equations (11) and (12) are fitted by regression analysis of the experimental results, with consideration of potential influencing parameters including concrete strength $f_{\mathrm{c}}$, PVA fiber content $m_{\mathrm{f}}$, elastic modulus $E_{\mathrm{c}}$ and peak strain $\varepsilon_{\mathrm{cr}}$. The stress-strain expression calculated by the proposed model for all the specimen groups tested in this work and the determination approach for critical parameter $a$ and $b$ are shown in Table 10. In addition, the predicted stress-strain curves for experimental specimens using Equations (11) and (12) and the proposed the determination approach for critical parameter $a$ and $b$ in Table 10 is shown in Figure 17.

Table 10. Determination of parameters $a$ and $b$.

\begin{tabular}{|c|c|c|c|c|c|c|c|c|c|c|c|}
\hline Types & Model & Parameter & $\mathrm{C} 25$ & C30 & C35 & $\mathrm{C} 40$ & FC1 & FC2 & FC3 & FC4 & Key Parameter Value \\
\hline $\begin{array}{l}\text { Ascend } \\
\text { stage }\end{array}$ & $y=\frac{(a+1)}{a+x^{a+1}}$ & $a$ & 21.84 & 22.48 & 30.64 & 28.53 & 21.62 & 17.52 & 14.36 & 18.47 & $a=\frac{\left(0.1642 m_{\mathrm{f}}^{2}-1.213 m_{\mathrm{f}}+3.2\right)}{\left(1-f_{\mathcal{C}} /\left(E_{\mathcal{C}} \varepsilon_{\mathrm{cr}}\right)\right)}$ \\
\hline $\begin{array}{l}\text { Decline } \\
\text { stage }\end{array}$ & $y=\frac{x}{b(x-1)^{2}+x}$ & $\begin{array}{l}R^{2} \\
b \\
R^{2}\end{array}$ & $\begin{array}{l}0.999 \\
39.68 \\
0.990\end{array}$ & $\begin{array}{l}0.999 \\
50.67 \\
0.989\end{array}$ & $\begin{array}{l}0.999 \\
65.80 \\
0.985\end{array}$ & $\begin{array}{l}0.999 \\
51.64 \\
0.968\end{array}$ & $\begin{array}{l}0.999 \\
48.75 \\
0.969\end{array}$ & $\begin{array}{l}0.999 \\
33.29 \\
0.981\end{array}$ & $\begin{array}{l}0.998 \\
29.50 \\
0.987\end{array}$ & $\begin{array}{l}0.998 \\
45.41 \\
0.959\end{array}$ & $\begin{array}{l}R^{2}=0.9407 \\
b=\left(0.0011 m_{\mathrm{f}}^{2}-0.0083 m_{\mathrm{f}}+0.0256\right) f_{\mathrm{c}}^{2} \\
R^{2}=0.7676\end{array}$ \\
\hline
\end{tabular}

Note: $R^{2}$ refers to the fitting degree of regression line to corresponding data.

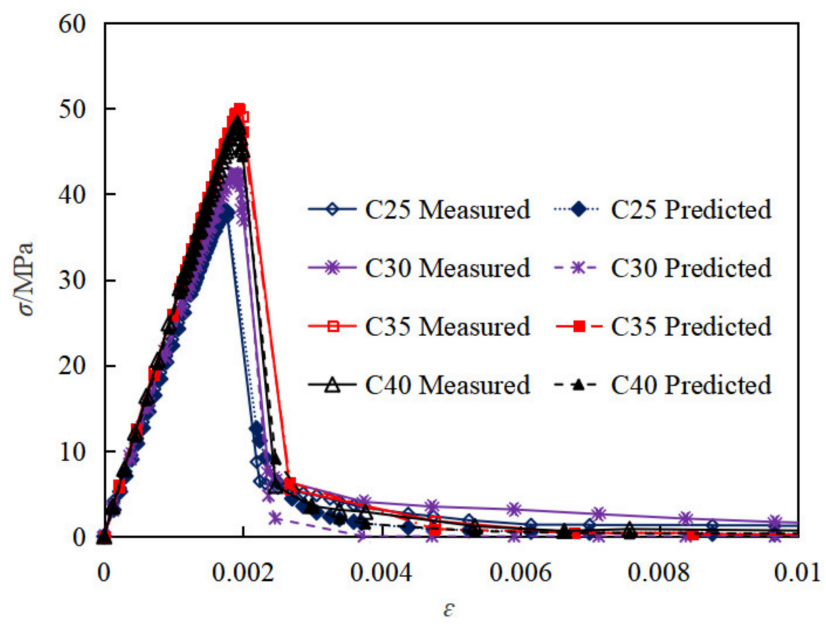

(a)

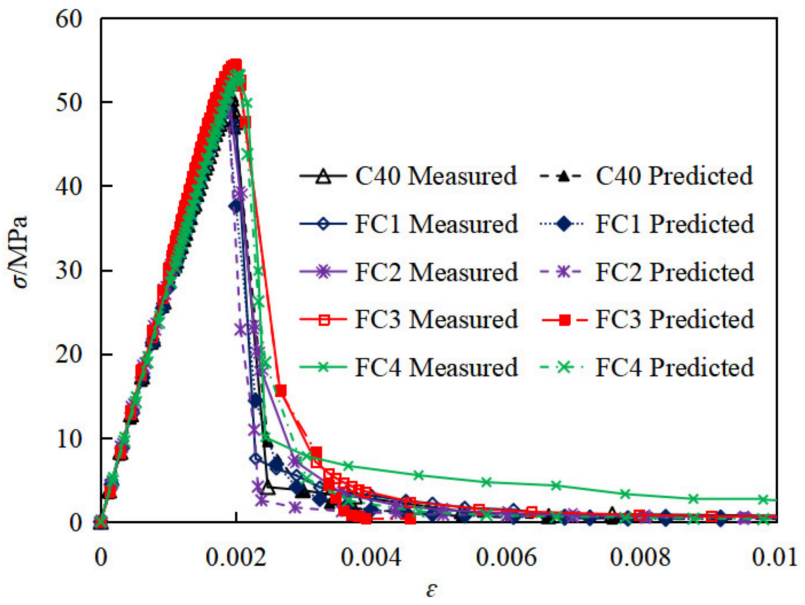

(c)

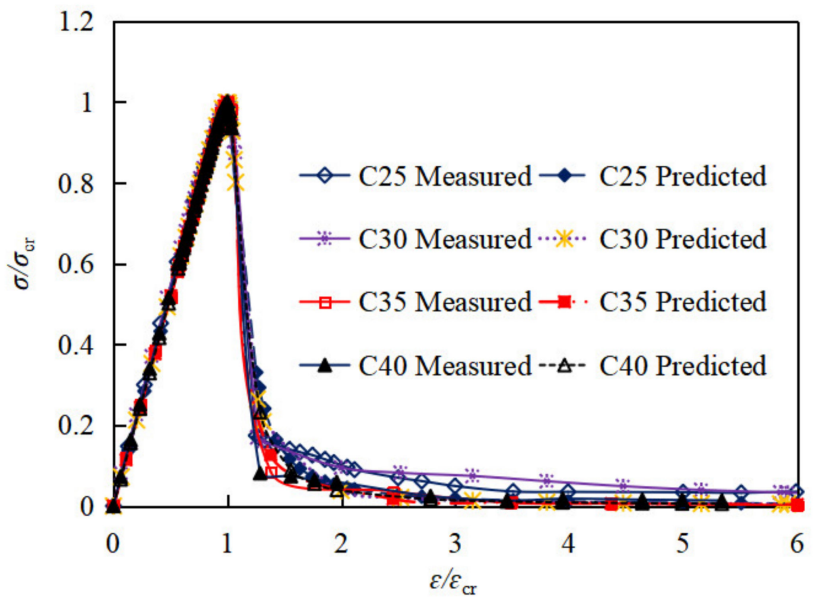

(b)

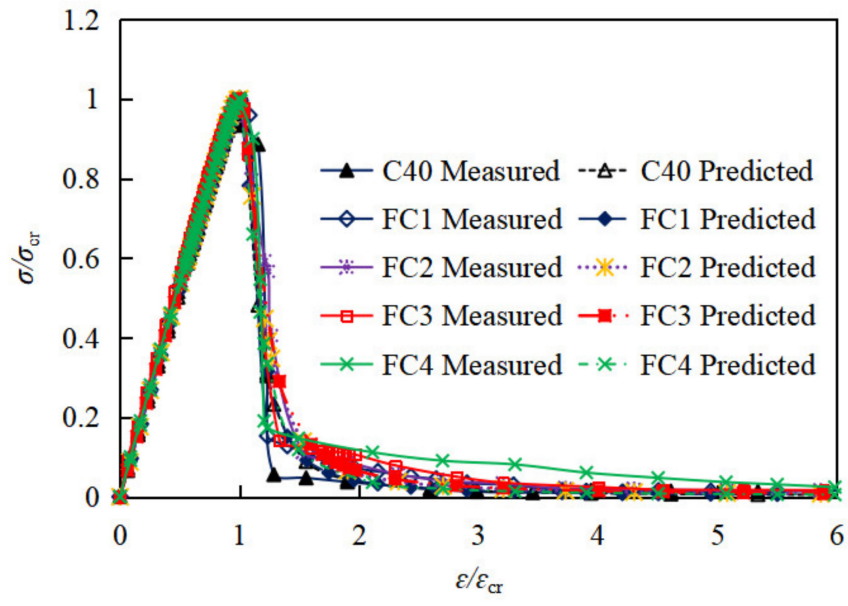

(d)

Figure 17. Fitting effect of model prediction. (a) Different strengths, (b) Different strengths (dimensionless), (c) Different fiber content, (d) Different fiber content (dimensionless). 
As shown in Table 10 and Figure 17, the coefficients of determination $\left(R^{2}\right)$ of both the ascending and descending stages are greater than 0.95 , and the predicted results of the proposed model are in good agreement with the experimental results. Thus, it can be concluded that the proposed model and the suggested determination approach of parameter $a$ and $b$ are capable of accurately describing the constitutive relationship of plain and PVA fiber-reinforced coral concrete.

In addition, the best PVA fiber content for coral concrete with different compressive strength is also analyzed using Equations (11) and (12) and the suggested determination approach of parameter $a$ and $b$ in Table 10, as shown in Figure 18. With an increase of the concrete strength, the parameters $a$ and $b$ increase correspondingly, meaning that the brittleness index $\beta$ increases and the toughness index $\delta$ decreases. As is known from experimental results, with increasing concrete strength, the elastic modulus and the brittleness of concrete also increases, evidencing that the prediction approach gives good consideration of the influence of concrete strength. In addition, with the increase of PVA fiber content, the parameter $a$ and $b$ decrease firstly when $V_{\mathrm{f}}$ does not exceed $4 \mathrm{~kg} / \mathrm{m}^{3}$, and then increase after $m_{\mathrm{f}}$ exceeds $4 \mathrm{~kg} / \mathrm{m}^{3}$. As presented above, the smaller parameter $a$ and $b$, the better toughness and smaller brittleness of coral concrete. That is to say, the best content of PVA fiber may be about $4 \mathrm{~kg} / \mathrm{m}^{3}$, which coincides with the experimental results. This phenomenon could be attributed to the bridging effect of PVA fiber, which effectively prevents the expansion of transverse cracks and consumes energy when fracture. However, when the fiber content is too large, it would cause fiber winding and clusters, forming weak areas in the coral concrete, resulting in the reduction of fiber toughening effect. As shown in Figure 18, with an increase of concrete strength, the best content of PVA fiber increases slightly around $4 \mathrm{~kg} / \mathrm{m}^{3}$. Therefore, the best content of PVA fiber can be suggested as $4 \mathrm{~kg} / \mathrm{m}^{3}$ regardless of concrete strength.

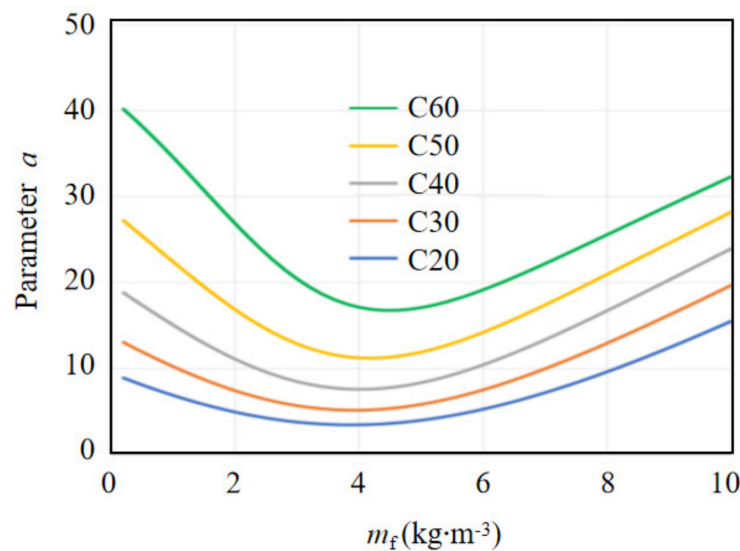

(a)

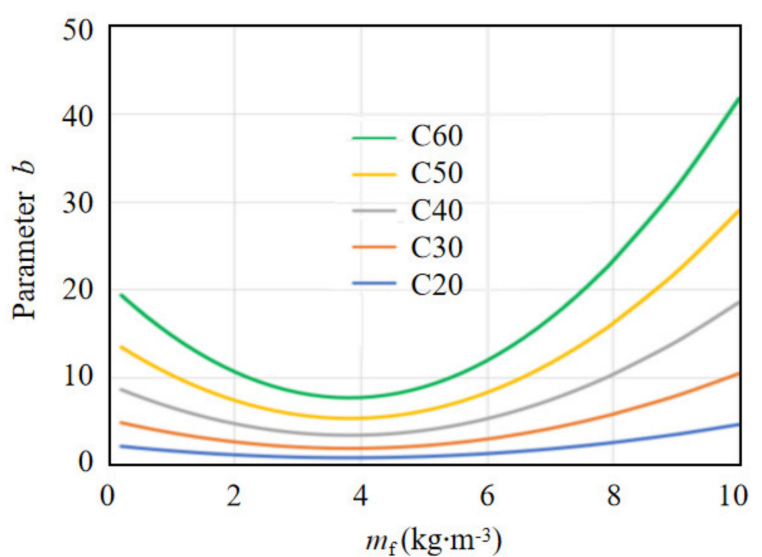

(b)

Figure 18. The relationship between model parameters and fiber content and concrete strength. (a) Parameter $a$, (b) Parameter $b$.

\section{Conclusions}

1. According to a certain proportion of silica fume, slag, P.O. 42.5 cement, coral coarse and fine aggregate, artificial sea water, etc., coral aggregate-seawater concrete with the compressive strength of 30 to $50 \mathrm{MPa}$ and good performance can be prepared.

2. With an increase of PVA fiber content, the slump and dispersion of coral concrete decreases significantly. In order to ensure the working performance of coral concrete, it is suggested that the PVA fiber content of coral concrete should not exceed $5 \mathrm{~kg} / \mathrm{m}^{3}$ in marine environment construction, and not exceed $2 \mathrm{~kg} / \mathrm{m}^{3}$ if using pumping construction.

3. With increasing strength of coral concrete, the elastic modulus, Poisson's ratio and peak strain increase, but the residual stress and the toughness decrease. 
4. PVA fiber effectively improves the compression strength of coral concrete, as well as the ductility and mechanical properties after peak load. Compared with the reference coral concrete, the maximum growth rate of cubic compressive strength $f_{\mathrm{cu}}$ is up to $9.9 \%$. The optimal amount of PVA fibers to optimize mechanical properties of coral concrete is about $2-3 \mathrm{~kg} / \mathrm{m}^{3}$.

5. PVA fiber has remarkable effect on improving the toughness of coral concrete. When the fiber content ranges from 0.8 to $6.5 \mathrm{~kg} / \mathrm{m}^{3}$, the toughness index $\delta$ of coral concrete increase by $2.9 \%$ to $10.1 \%$, and the brittleness index $\beta$ decreases by $15.3-28.8 \%$.

6. The constitutive relationship of plain and PVA fiber-reinforced coral concrete can be described by the recommended piecewise function model and the proposed approach to determining critical parameter $a$ and $b$. In addition, through analysis of the model, the optimal PVA fiber content of coral concrete may be $4 \mathrm{~kg} / \mathrm{m}^{3}$.

7. To meet the requirements of structure design and environmental benefits, it plays a very important guiding role in the engineering application of coral concrete to optimize the mix ratio design and improve the corrosion resistance, high temperature resistance and drying shrinkage resistance of coral concrete structure. However, more validation experiments are needed though.

Author Contributions: Conceptualization, Methodology, Investigation, Formal analysis, Writingoriginal draft preparation, Writing-review and editing, L.R.; Conceptualization, Formal analysis, Validation, L.W.; Resources, Methodology, Y.Z. All authors have read and agreed to the published version of the manuscript.

Funding: This research was funded by the National Natural Science Foundation of China (51890903), Henan Province Young Backbone Teacher Training Plan of China (2019GZGG075), the National Key Research Program of China (2017YFC0703403), Collaborative Innovation Center for New EnergySaving Building Materials of Kaifeng University, Solid waste recycling and harmless Engineering Technology Research Center of Kaifeng.

Data Availability Statement: All data reported in this paper is contained within the manuscript.

Acknowledgments: The authors would like to thank the National Natural Science Foundation of China (51890903), the Henan Province Young Backbone Teacher Training Plan of China (2019GZGG075), the National Key Research Program of China (2017YFC0703403), Collaborative Innovation Center for New Energy-Saving Building Materials of Kaifeng University, Solid waste recycling and harmless Engineering Technology Research Center of Kaifeng.

Conflicts of Interest: The authors declare no conflict of interest.

\section{References}

1. Dempsey, G. Coral and salt water as concrete materials. J. Am. Concr. Inst. 1951, 48, 157-166.

2. Narver, D.L. Good concrete made with coral and water. Civ. Eng. 1964, 24, 654-858.

3. Ehlert, R. Coral concrete at bikini atoll. Concr. Int. 1991, 13, 19-24.

4. Howdyshell, P.A. The Use of Coral as an Aggregate for Portland Cement Concrete Structures; Army Construction Engineering Research Laboratory: Champaign, IL, USA, 1974.

5. Yuan, Y.F. Mix Design and Property of Coral Aggregate Concrete. Master's Thesis, Nanjing University of Aeronautics and Astronautics, Nanjing, China, 2015. (In Chinese)

6. Zhang, Z.H.; Sang, Z.Q.; Zhang, L.Y.; Ma, Z.X.; Zhang, Y. Experimental Research on Durability of Concrete Made by Seawater and Sea-Sand. Adv. Mater. Res. 2013, 641-642, 385-388. [CrossRef]

7. Wang, Y.; Zhang, S.; Niu, D.; Su, L.; Luo, D. Effects of silica fume and blast furnace slag on the mechanical properties and chloride ion distribution of coral aggregate concrete. Constr. Build. Mater. 2019, 214, 648-658. [CrossRef]

8. Sun, Z.X. Engineering properties of coral sand in Nansha Islands. Trop. Ocean 2000, 19, 1-8. (In Chinese).

9. Liu, J.; Ou, Z.; Peng, W.; Guo, T.; Deng, W.; Chen, Y. Literature Review of Coral Concrete. Arab. J. Sci. Eng. 2018, 43, 1529-1541. [CrossRef]

10. Cheng, S.; Shui, Z.H.; Sun, T.; Yu, R.; Zhang, G. Durability and microstructure of coral sand concrete incorporating supplementary cementitious materials. Constr. Build. Mater. 2018, 171, 44-53. [CrossRef]

11. Bentz, D. Influence of internal curing using lightweight aggregates on interfacial transition zone percolation and chloride ingress in mortars. Cem. Concr. Compos. 2009, 31, 285-289. [CrossRef] 
12. De Domenico, D.; Faleschini, F.; Pellegrino, C.; Ricciardia, G. Structural behavior of RC beams containing EAF slag as recycled aggregate: Numerical versus experimental results. Constr. Build. Mater. 2018, 171, 321-337. [CrossRef]

13. Le, H.B.; Bui, Q.B. Recycled aggregate concretes-a state-of-the-art from the microstructure to the structural performance. Constr Build. Mater. 2020, 257, 119522. [CrossRef]

14. Mukhopadhyay, S.; Khatana, S. A review on the use of fibers in reinforced cementitious concrete. J. Ind. Text. 2015, 45, 239-264. [CrossRef]

15. Pereira, E.B.; Fischer, G.; Barros, J.A. Effect of hybrid fiber reinforcement on the cracking process in fiber reinforced cementitious composites. Cem. Concr. Compos. 2012, 34, 1114-1123. [CrossRef]

16. Nia, A.A.; Hedayatian, M.; Nili, M.; Afroughsabet, V. An experimental and numerical study on how steel and polypropylene fibers affect the impact resistance in fiber-reinforced concrete. Int. J. Impact Eng. 2012, 46, 62-73. [CrossRef]

17. Yoo, D.-Y.; Banthia, N.; Yoon, Y.-S. Impact Resistance of Reinforced Ultra-High-Performance Concrete Beams with Different Steel Fibers. ACI Struct. J. 2017, 114, 113-124. [CrossRef]

18. Wang, L.; Liu, C.P.; Xiong, J.Z. Study test on mechanical property of sisal fiber reinforced coral concrete. J. Henan Polytech. Univ. 2014, 33, 826-830. (In Chinese)

19. Wang, L.; Deng, X.L.; Wang, G.X. Experimental research on the mechanical properties of carbon fiber coral concrete. Concrete 2014, 8, 88-91. (In Chinese)

20. Wang, L.; Yi, J.; Deng, X.L.; Li, J.Y. Study on mechanical property and damage morphology analysis of coral aggregate concrete with fiber. J. Henan Polytech. Univ. 2016, 35, 713-718. (In Chinese)

21. Wang, J.; Dai, Q.; Si, R.; Guo, S. Investigation of properties and performances of Polyvinyl Alcohol (PVA) fiber-reinforced rubber concrete. Constr. Build. Mater. 2018, 193, 631-642. [CrossRef]

22. Arisoy, B.; Wu, H.-C. Material characteristics of high performance lightweight concrete reinforced with PVA. Constr. Build. Mater. 2008, 22, 635-645. [CrossRef]

23. Passuello, A.; Moriconi, G.; Shah, S.P. Cracking behavior of concrete with shrinkage reducing admixtures and PVA fibers. Cem. Concr. Compos. 2009, 31, 699-704. [CrossRef]

24. Noushini, A.; Samali, B.; Vessalas, K. Effect of polyvinyl alcohol (PVA) fiber on dynamic and material properties of fiber reinforced concrete. Constr. Build. Mater. 2013, 49, 374-383. [CrossRef]

25. ASTM C33/C33M-18; Standard Specification for Concrete Aggregates. American Society for Testing and Materials: West Conshohocken, PA, USA, 2018.

26. GB/T 17431.2-2010; Light Aggregates and Test Methods-Part 2: Light Aggregate Test Method. AQSIQ and SAC (General Administration of Quality Supervision, Inspection and Quarantine/Standardization Administration of the People's Republic of China): Beijing, China, 2010. (In Chinese)

27. Da, B.; Yu, H.; Ma, H.; Tan, Y.; Mi, R.; Dou, X. Experimental investigation of whole stress-strain curves of coral concrete. Constr Build. Mater. 2016, 122, 81-89. [CrossRef]

28. JGJ/T 12-2019; Technical Standard for Application of Lightweight Aggregate Concrete. China Architecture \& Building Press: Beijing, China, 2002. (In Chinese)

29. CECS13: 2009; Standard for Test Methods for Fiber Reinforced Concrete. China Planning Press: Beijing, China, 2009. (In Chinese)

30. Wang, L.; Fan, L. Analysis of strength characteristics and failure modes of coral debris concrete. China Concr. Cem. Prod. 2015, 1, 1-4. (In Chinese)

31. Liu, J.; Ou, Z.; Mo, J.; Chen, Y.; Guo, T.; Deng, W. Effectiveness of Saturated Coral Aggregate and Shrinkage Reducing Admixture on the Autogenous Shrinkage of Ultrahigh Performance Concrete. Adv. Mater. Sci. Eng. 2017, 2017, 1-11. [CrossRef]

32. Li, L.; Zhao, Y.L.; Lu, H.B.; Han, C. Coral aggregate pre-wet on the mechanical properties of concrete. Concrete 2011, 1, 85-86. (In Chinese)

33. GB/T 50081-2019; Standard for Method of Mechanical Properties on Ordinary Concrete. China Architecture and Building Press: Beijing, China, 2019. (In Chinese)

34. GB/T 50080-2016; Standard for Test Method of Performance on Ordinary Fresh Concrete. China Architecture \& Building Press: Beijing, China, 2017. (In Chinese)

35. GB 50164-2011; Standard for Quality Control of Concrete. China Architecture \& Building Press: Beijing, China, 2012. (In Chinese)

36. GB50666-2011; Code for Construction of Concrete Structure. China Architecture \& Building Press: Beijing, China, 2011. (In Chinese)

37. ASTM C 469; Standard Test Method for Static Modulus of Elasticity and Poisson's Ratio of Concrete. ASTM International: West Conshohocken, PA, USA, 2014

38. Wang, S.H. Research of Material Confect and Property of High Strength and High Content Hybrid Fiber Reinforced Concrete Master's Thesis, Tongji University, Shanghai, China, 2007. (In Chinese)

39. Liu, H.W. Mechanics of Materials; Higher Education Press: Beijing, China, 1997. (In Chinese)

40. Li, J.J.; Niu, J.G.; Liu, H.Z.; Zhu, C.; Zhang, Z. Comparative study of evaluation methods for toughness index in steel fiber reinforced lightweight aggregate concrete. Build. Struct. 2016, 46, 39-42. (In Chinese)

41. ASTM-C 1018-97; Standard Test Method for Flexural Toughness and First-Crack Strength of Fiber Reinforced Concrete. ASTM International: West Conshohocken, PA, USA, 1997.

42. Liu, X.; Wu, T.; Liu, Y. Stress-strain relationship for plain and fibre-reinforced lightweight aggregate concrete. Constr. Build. Mater. 2019, 225, 256-272. [CrossRef] 
43. Guo, Z.H.; Zhang, X.Q. Stress-strain full curves of concrete under cyclic loading. Ind. Constr. 1981, 11, 13-17. (In Chinese)

44. Yang, K.-H.; Mun, J.-H.; Cho, M.-S.; Kang, T.H.-K. Stress-Strain Model for Various Unconfined Concretes in Compression. ACI Mater. J. 2014, 111, 819-826. [CrossRef]

45. Zhang, Y. Research on Dynamic and Static Mechanical Properties of Coral Aggregate Concrete. Master's Thesis, Nanjing University of Aeronautics and Astronautics, Nanjing, China, 2016. (In Chinese)

46. Zhao, M.S. Stress-Strain Behaviors of Steel Fiber Reinforced Full-Lightweight Concrete under Compression. Master's Thesis, North China University of Water Resources and Electric Power, Zhengzhou, China, 2016. (In Chinese)

47. GB50010-2010; Code for Design of Concrete Structures. China Architecture \& Building Press: Beijing, China, 2011. (In Chinese)

48. Shannag, M. Characteristics of lightweight concrete containing mineral admixtures. Constr. Build. Mater. 2011, $25,658-662$. [CrossRef] 